\title{
Single cell analysis of the cellular heterogeneity and interactions in the injured mouse spinal cord
}

Lindsay M Milich ${ }^{1,2, \#, ~ J a m e s ~ C h o i ~}{ }^{1, \#}$, Christine Ryan ${ }^{1,2}$, Stephanie L Yahn ${ }^{1,2}$, Pantelis Tsoulfas ${ }^{1}$, Jae K Lee ${ }^{1}$

${ }^{1}$ University of Miami School of Medicine, Miami Project to Cure Paralysis, Department of Neurological Surgery, Miami, FL 33136, '2University of Miami Neuroscience Graduate Program

\#These authors contributed equally

Corresponding author:

Jae K. Lee, PhD

University of Miami School of Medicine

Miami Project to Cure Paralysis

Department of Neurological Surgery

1095 NW 14 ${ }^{\text {th }}$ Terrace

LPLC 4-19

Miami, FL, 33136

305-243-2646

JLee22@med.miami.edu 


\begin{abstract}
The wound healing process that occurs after spinal cord injury is critical for maintaining tissue homeostasis and limiting tissue damage, but eventually results in a scar-like environment that is not conducive to regeneration and repair. A better understanding of this dichotomy is critical to developing effective therapeutics that target the appropriate pathobiology, but a major challenge has been the large cellular heterogeneity that results in immensely complex cellular interactions. In this study, we used single cell RNA sequencing to assess virtually all cell types that comprise the mouse spinal cord injury site. In addition to discovering novel subpopulations, we used expression values of receptor-ligand pairs to identify signaling pathways that potentially drive specific cellular interactions during angiogenesis, gliosis, and fibrosis. Our dataset is a valuable resource that provides novel mechanistic insight into the pathobiology of not only spinal cord injury, but also other traumatic disorders of the CNS.
\end{abstract}




\section{Main}

In the adult mammalian nervous system, a diverse population of glial and vascular cells are essential for optimal neuronal function. After spinal cord injury ( $\mathrm{SCl})$, this cellular diversity becomes even more heterogeneous by infiltrating leukocytes, which trigger a cascade of events collectively termed the wound healing process. The major research focus of the wound healing process after SCI has been its end-product, namely the formation of scar-like tissue in and around the lesion epicenter. However, we have a limited knowledge of the heterogeneity of the cells that comprise the injury site and how these cells interact during the wound healing process after $\mathrm{SCl}$.

$\mathrm{SCl}$ triggers multiple processes that occur in a temporally defined manner. At 1 day post-injury (dpi), an innate immune response initiated by microglia is expanded by peripheral myeloid cells, mainly neutrophils and monocytes, which migrate to the injury site ${ }^{1}$. By $3 d p i$, most glial cells including astrocytes, microglia, and oligodendrocyte progenitor cells (OPCs), are at the peak of their proliferative state, resulting in recovery of cell number and initiating gliosis ${ }^{2}$. Concurrently, monocytes differentiate into macrophages that phagocytose cellular debris, acquire different phenotypic states, and activate perivascular fibroblasts to initiate fibrosis ${ }^{3}$. By $7 \mathrm{dpi}$, the number of macrophages and fibroblasts have reached their peak, and the fibrotic scar begins to be surrounded by the astroglial scar, which limit their infiltration into the spinal cord parenchyma ${ }^{4}$. In addition, during these first 7 days, hypoxic conditions at the injury site promote angiogenesis and revascularization ${ }^{5}$. By 14dpi, gliosis, fibrosis, and angiogenesis have reached a more stable state $^{5-7}$. Thus, the first 7 days after injury is highly dynamic, and provide a window of therapeutic intervention for multiple pathological processes, but we currently have a limited understanding of the cellular interactions that occur during this critical period.

One way to investigate cellular responses to injury is through transcriptomic profiling of cell types that comprise the injury site. Traditional methods of using FACS, or more recent methods utilizing 
immunoprecipitation of cell type-specific polyribosomes or nuclei have provided important insight into CNS pathobiology ${ }^{8,9}$. However, these studies have been limited by the focus on a single cell type as well as the lack of information on subpopulation heterogeneity and different cell states. Recent advances in single cell RNA-sequencing (sc-RNAseq) technologies have circumvented these limitations by providing a more accurate depiction of the heterogeneous subpopulations that comprise a single cell type. In addition, many different cell types can be obtained and analyzed from a single tissue sample simultaneously, enabling examination of relationships and signaling mechanisms between multiple cell types.

In this study, we used sc-RNAseq to generate a single cell transcriptomics dataset of virtually all cell types that comprise the uninjured and injured spinal cord at 1, 3, and 7dpi. From this dataset, we were able to obtain unique molecular signatures of multiple cell types as well as their subpopulations present throughout the acute injury phase. By assessing expression of ligandreceptor pairs on different cell types, we were able to gain insight into potential signaling relationships that mediat angiogenesis, gliosis, and fibrosis. As the first sc-RNAseq analysis of the spinal cord injury site, our transcriptomic dataset will provide the field with novel and comprehensive insight into early spinal cord injury pathology as well as other traumatic injuries to the CNS.

\section{Results}

\section{Molecular identification of immune, vascular, and glial cells in the acute injury site}

To assess the cellular heterogeneity among all cell populations at the injury site, we obtained a total of 51,843 cells from uninjured and 1,3 , and 7 dpi tissue, which resulted in a total of 15 distinct clusters when visualized on a UMAP plot (Fig. 1a, b). These 15 clusters represented all major cell types that are known to comprise the $\mathrm{SCl}$ site including microglia, monocytes, macrophages, neutrophils, dendritic cells, astrocytes, oligodendrocytes, OPCs, neurons, fibroblasts, pericytes, 
ependymal cells, and endothelial cells. These cell types were grouped into three categories, namely myeloid, vascular, and macroglia, for further analysis as described below. Neurons were excluded from the analysis because they were not expected to survive our dissociation protocol and thus subject to a selection bias. Lymphocytes were also excluded because they are primarily involved in autoimmunity after $\mathrm{SCl}^{10}$, which is beyond the scope of this study. Cell types pertaining to each cluster were identified using annotated lineage markers (Extended Data Fig. 1).

The highest differentially expressed genes (DEGs) provided a unique molecular signature for each cell type (Fig. 1c, d), which in most cases were different from canonical markers used in the literature. For example, the highest DEGs in OPCs were non-canonical genes such as $t n r$ (Tenascin-R) and Ihfp/3 (lipoma HMGIG fusion partner), which displayed better specificity than canonical OPC markers such as pdgfra and cspg4 that were expressed in multiple cell types (Extended Data Fig. 1). Interestingly, while certain marker genes were expressed both before and after injury, others such as postn in fibroblasts, changed expression in an injury-dependent manner. While postn was not expressed in uninjured fibroblasts, there was a graded increase as injury progressed (Fig. 1c). We validated this by genetic lineage tracing in Postn ${ }^{\mathrm{EYFP}}$ mice, which showed EYFP cells present in the fibrotic scar and overlying meninges but absent in surrounding spinal cord tissue. (Extended Data Fig. 2). Taken together, our analysis of DEGs between major cell types uncovers highly specific molecular identifiers, many of which are non-canonical and display temporal specificity.

\section{Myeloid analysis reveals temporal changes in macrophage and microglial subtypes}

To determine the heterogeneity within the myeloid population, clustering analysis was performed on myeloid cells and visualized on a separate UMAP (Fig. 2a, b), which revealed two large clusters corresponding to microglia and peripherally-derived myeloid cells as identified by annotated markers (Extended Data Fig. 3). We identified 6 microglial subtypes. Homeostatic 
microglia were identified based on its expression of several annotated markers of steady-state microglia, such as p2ry12, siglech, and tmem119 (Fig. 2). As expected, homeostatic microglia were the predominant myeloid population in the uninjured spinal cord, but by $1 \mathrm{dpi}$ they were replaced by microglia subtypes similar to previously reported Disease-Associated Microglia (DAM) (Fig. 2b, c) ${ }^{11}$. We identified four DAM subtypes, which were labeled DAM-A to D. DAM-A was identified by high expression of the low density lipoprotein receptor $m s r 1$ and low expression of the purinergic receptor $p 2 r y 12$, and comprised $100 \%$ of microglia present at $1 \mathrm{dpi}$. DAM-B and C expressed moderate level of p2ry12 and low level of $m s r 1$, and their expression profile was similar to homeostatic microglia, suggesting an intermediate state as some DAM-A revert back to a more homeostatic state. DAM-D had low levels of both $m s r 1$ and $p 2 r y 12$, and was best identified by high expression of the growth factor igf1 and the cholesterol-binding protein apoe. The last microglia subtype was identified as dividing microglia due to their high expression of cell cyclerelated genes (mki67 and top2a). Dividing microglia shared several DEGs with DAM-D such as igf1, spp1, and fabp5 (Fig. 2e), and the fact that expansion of DAM-D from 3 to 7 dpi coincides with reduction in dividing microglia (Fig. 2c) suggests that dividing microglia may give rise to DAMD after injury. A putative model depicting the relationship between DAM subtypes is illustrated in Extended Data Fig. 4a.

We used flow cytometry to validate the presence of DAMs in vivo (gating strategy in Extended Data Fig 5). We focused on DAM-A due to its distinct molecular signature as compared to homeostatic microglia (Fig. 2), and its dramatic appearance and disappearance between 1dpi and 3dpi (Fig. 2b, c). Microglia were gated on P2ry12 and Msr1 expression based on our sequencing data (Fig. 2d). As expected, over $90 \%$ of microglia present in the uninjured spinal cord were in the homeostatic state (P2ry12 ${ }^{\mathrm{hi} / \mathrm{Msr} 1^{\mathrm{lo}}}$ ), and this decreased to $20 \%$ at $1 \mathrm{dpi}$ (Fig. $2 \mathrm{f}$, g). At $1 \mathrm{dpi}$, there was a large increase in Msr1 ${ }^{\text {hi }}$ microglia, consistent with the appearance of DAMA. However, the majority of Msr1 ${ }^{\text {hi }}$ microglia were also P2ry $12^{\text {hi }}$, representing a transition state 
between homeostatic and DAM-A, which are expected to be P2ry12\%/Msr $1^{\text {hi }}$ based on our sequencing results. At 7dpi, we observed a significant decrease in Msr1 ${ }^{\text {hi }}$ microglia and a partial return of homeostatic microglia, which this was not observed in our sequencing data. Taken together, our flow cytometry data support the appearance of DAM-A microglia subtype after SCI in vivo, but the temporal effects are more graded than those predicted from our sequencing data perhaps due to a delay in manifestation of gene expression changes at the protein level.

The peripherally-derived myeloid cluster revealed two monocyte and two macrophage subtypes in addition to border-associated macrophages and dendritic cells. The two monocyte subtypes corresponded to the classical Ly6C hi and the non-classical Ly6Clo monocytes (Fig. 3c) with the latter representing the largest population at $1 \mathrm{dpi}$. 3 and $7 \mathrm{dpi}$ were dominated by the two macrophage subtypes, Macrophage-A and Macrophage-B respectively. Although these two subtypes did not correspond to the M1/M2 nomenclature ${ }^{12}$ (Extended Data Fig. 5), MacrophageA expressed higher levels of the anti-inflammatory marker arg1 than Macrophage-B (Fig. 3, Extended Data Fig. 5). This was consistent with Gene Ontology (GO) terms associated with inflammation being prevalent in Macrophage-B (Extended Data Fig 5). Both subtypes expressed the lysosomal gene cd63, but were distinguished by preferential expression of heme oxygenase hmox in Macrophage-A and apoe in Macrophage-B. In conclusion, our data reveals the presence of multiple cellular states in the monocyte-macrophage lineage that display temporal progression toward a more pro-inflammatory state. A putative minimal model depicting the relationship between these subtypes is illustrated in Extended Data Fig. 4b.

To validate the presence of Macrophage-A and Macrophage-B subtypes in vivo, we first isolated macrophages based on CD63 ${ }^{\text {hi }}$ expression (gating strategy in Extended Data Fig. 6). Further separation on ApoE and CD11b expression revealed two distinct clusters that were consistent with Macrophage-A (CD63 $\left.3^{\text {hi}} / A p o E^{\text {lo }} / C D 11 b^{\text {med }}\right)$ and Macrophage-B (CD63 $\left.{ }^{\text {hi}} / A p o E^{h i} / C D 11 b^{\text {hi}}\right)$ 
subtypes (Fig. 3d, e). Consistent with our sequencing data, the monocytes were the predominant myeloid populations at $1 \mathrm{dpi}$, and subsequently decreased at $7 \mathrm{dpi}$, whereas Macrophage-A $\left(A p o E^{l o}\right)$ and Macrophage-B $\left(A p o E^{h i}\right)$ were the most represented macrophage subtypes at 1 and 7dpi, respectively (Fig. 3e). Therefore, the flow cytometry data support the molecular identification of Macrophage-A and Macrophage-B subtypes and their temporal progression after $\mathrm{SCl}$ in vivo. In summary, analysis of myeloid cells reveal novel subtypes of microglia and macrophages during $\mathrm{SCl}$ progression.

\section{Vascular heterogeneity analysis identifies tip cell dynamics}

To determine the heterogeneity of vascular cells, clustering analysis was performed only on the vascular clusters (endothelial cells, fibroblasts, and pericytes from Fig. 1) and visualized on a separate UMAP, which revealed endothelial cell subtypes on one side and perivascular mural cells on the other. We identified each cluster using annotated markers from a previous sc-RNAseq study of the brain vasculature ${ }^{13}$. We identified fibroblasts, pericytes, and vascular smooth muscle cells (VSMC) as three distinct populations of perivascular mural cells that were identified based on their expression of col1a1, kcnj8, and acta2 respectively (Extended Data Fig. 7b). We also identified an unknown vascular subtype (U-Vascular) that clustered with mural cells due to its molecular similarity with pericytes, but also expressed endothelial cell markers (Extended Data Fig. 7c). Analysis of whether this could have been due to capture of two different cell types (i.e. doublet) during single cell processing indicated that this was not likely.

Next, we identified an arterial, a venous, and two capillary subtypes based on annotated markers ${ }^{13}$. Arterial endothelial cells were identified by expression of $g k n 3$ and stmn2, whereas venous endothelial cells were identified by s/c38a5 and icam1. Capillary endothelial cells were identified by the expression of general endothelial cell markers ly6a and cldn5, combined with the lack of selective arterial and venous markers (Fig. 4d, Extended Data Fig. 7c). The fifth endothelial 
cluster was identified as tip cells based on their expression of the canonical marker apln. Tip cells are leading cells present during vasculogenesis and angiogenesis, and they have not yet been systematically assessed in $\mathrm{SCl}$. Whereas the other endothelial subtypes did not show large temporal changes in proportion, the proportion of tip cells increased significantly at $1 \mathrm{dpi}$, and decreased to basal levels by $7 \mathrm{dpi}$ (Fig. 4c). This tip cell temporal profile was validated using in situ hybridization for apln combined with immunostaining for podocalyxin as an endothelial cell marker (Fig 4f). In the uninjured cord, apln transcripts were detected scattered throughout the gray matter, consistent with previous reports of apln expression in neurons ${ }^{14}$. However, we did not detect any endothelial cells expressing apln in uninjured tissue sections, suggesting that tip cells detected in uninjured tissue in our sc-RNAseq data was most likely due to tissue processing. Taken together, our analysis identified all known major vascular cell types at the injury site, including previously undescribed tip cell molecular and temporal profiles.

\section{Cellular interactions via angiopoietin and VEGF signaling during angiogenesis}

To gain insight into mechanisms of cellular interactions during angiogenesis after SCl, we adapted CellPhoneDB" to calculate "interaction scores" based on the average expression levels of a ligand and its receptor between two cells (Fig. 5a). Higher interaction scores indicate stronger predicted interactions between two cells via the specified ligand-receptor pathway. We focused on angiopoietin (Angpt) and vascular endothelial growth factor (Vegf) signaling due to their wellknown roles in angiogenesis. Angpt1 is an agonist that promotes stabilization, whereas Angpt2 is an antagonist that promotes destabilization of blood endothelium by binding to the Tie2 receptor $^{16}$. Endothelial subtypes did not show any significant differences in these ligand or receptor expression, and therefore were collapsed into a single endothelial category for simplification. The highest interaction score was detected between tip cells and endothelial cells along the Angpt2Tie2 pathway at 1dpi (Fig. 5b). Expression analysis showed that Angpt2 is expressed most highly by tip cells at $1 \mathrm{dpi}$ followed by a gradual decrease over the next 7 days, and Tie2 (and Tie1) is 
expressed in endothelial cells at all time points (Fig. 5c). Pericytes and fibroblasts also contributed to this signaling interaction with endothelial cells, albeit at a lower level. These data suggest that Angpt2 has a dual role by autocrine signaling in tip cells that mediates their generation and behavior, as well as by paracrine signaling that destabilizes non-functional vessels. Interestingly, Angpt1 signaling to endothelial/tip cells shifted from VSMC at 1dpi to astrocytes at 3 and $7 \mathrm{dpi}$ (Fig. 5b). This corresponded to a shift in Angt1 expression from VSMC to astrocytes after injury (Fig. 5c), suggesting that astrocytes are important in vessel stabilization. Collectively, our data suggest that both vascular and neural cells interact with endothelial cells via Angpt signaling after $\mathrm{SCl}$, with tip cells promoting vessel destabilization during early angiogenesis, and with astrocytes mediating vessel stabilization at later periods.

Vegfa binding to Vegfr1 and Vegfr2 on endothelial cells facilitates the proliferation, survival and directional sprouting of tip cell filipodia during angiogenesis ${ }^{17-19}$. The highest interaction scores for these ligand-receptor pairs were associated with monocytes/macrophages and astrocytes (Fig. 5d). Vegfa expression was highest in these two cell types at 1dpi, and Vegfr1 and Vegfr2 receptors were highly expressed by endothelial cells at all time points, suggesting that the major cues for new vessel formation is derived from the infiltrating myeloid cells and astrocytes (Fig. 5e). Strikingly, the strongest interactions amongst the Vegf family members were associated with placental growth factor (Plgf) binding to Vegfr1 (Fig. 5d). Plgf mediates angiogenesis by binding to Vegfr120,21, and our expression analysis showed tip cells to be the primary source, although lower levels of Plgf were also expressed by fibroblasts, VSMC, and astrocytes (Fig. 5e). Similar to our Angpt analysis above, our Vegf analysis suggests that tip cells play a major role in facilitating their own migration and growth, as well as those of other endothelial cells. Collectively, our data provide a rational and temporal framework of how endothelial cells interact with infiltrating myeloid cells and astrocytes via Angpt and Vegf pathways to re-vascularize the injured tissue, 
and highlight the autocrine and paracrine effects of tip cells in this process. A minimal model of revascularization in the first week after $\mathrm{SCl}$ is illustrated in Fig $5 f$.

\section{Analysis of macroglia heterogeneity reveals astrocyte and OPC-specific roles during gliosis}

To assess macroglia heterogeneity, oligodendrocyte lineage cells, astrocytes, and ependymal cells were clustered and visualized on a separate UMAP (Fig. 6a, b), which showed spatial segregation corresponding to their major cell type. We identified three ependymal and an astroependymal subtypes with distinct expression and temporal profiles (Fig. 6c, e, Extended Data Fig 8). The astropendymal cells were best identified by their expression of the crystallin crym, and shared common markers with both astrocytes (e.g. timp1, gfap) and ependymal cells (e.g. vim, tmsb10). However, they did not express any cilia-associated genes that are hallmarks of ependymal cells (Extended Data Fig. 8c). The oligodendrocyte lineage cells segregated into previously described clusters that showed a spatial progression from OPC to dividing OPC and preoligodendrocytes, and finally to oligodendrocytes (Fig. 6a). These populations were identified by prototypical markers, with the exception of OPCs, which were best identified by tenascin $t n r$ (Fig. 6e, Extended Data Fig. 8b). Whereas mature oligodendrocytes were predominant in the uninjured spinal cord, the proportion of OPCs, dividing OPCs, and preoligodendrocytes gradually increased over the next $7 \mathrm{dpi}$. Taken together, our data highlight the heterogeneity of oligodendrocytes, astrocytes, and ependymal cells that reflect the effect of $\mathrm{SCl}$ on their differentiation state.

Although gliosis has been synonymous with reactive astrocytes, accumulating evidence indicates that OPCs are also an important component of the glial scar 22,23 . To compare reactive OPCs and astrocytes, we performed Gene Ontology (GO) Enrichment Analysis for biological processes associated with DEGs between each time point (Fig. 6f). At 1dpi, top biological processes for both astrocytes and OPCs pertain to translation and biogenesis. By 3dpi, astrocytes are defined by 
processes related to neurogenesis and gliogenesis, whereas OPCs are defined by mitosis, which reflect the active state of proliferation and differentiation for both cell types during this time. Interestingly, the DEGs between 3 and $7 \mathrm{dpi}$ in astrocytes were related to lipid processing, whereas those in OPCs were related to several processes including astrocyte development, synapse remodeling, and the inflammatory response, which are processes that have been typically associated with reactive astrocytes. To assess the potential effects of reactive astrocytes and OPCs on axonal growth, we compared the expression levels of axon growth inhibitory molecules using a previously curated list ${ }^{24}$ (Fig. 6g). Interestingly, inhibitory proteoglycans such as acan, bcan, ncan, and vcan were expressed preferentially by OPCs. In summary, our data suggest that although astrocytes and OPCs initially display similar generic responses to injury, by $7 \mathrm{dpi}$, they acquire unique functional identities, and many processes that have traditionally been attributed to reactive astrocytes are also present in OPCs.

\section{Macrophage-Mediated Mechanisms of Gliosis and Fibrosis}

Previous studies have shown that STAT3 plays an important role in astrogliosis ${ }^{4,25,26}$, but its upstream activators have yet to be clearly defined. Since IL6 cytokine family members are the main STAT3 activators, we assessed their expression across all cell types and found oncostatin $\mathrm{M}$ (osm) expressed at highest levels in myeloid cells, il6 expressed at highest levels in fibroblasts, and clcf1 expressed at highest levels in astroependymal cells (Fig. 7a). Other IL6 cytokines were either not expressed highly or dropped out of our sequencing analysis. Oncostatin M receptor (osmr) and the signaling coreceptor gp130 (il6st) were expressed highly in fibroblasts and astrocytes, and interaction scores for IL-6 cytokine family members were highest for OSM signaling between Ly6Clo monocytes/Macrophage-B and astrocytes/fibroblasts (Fig. 7b). To validate the sequencing data, we performed double in situ hybridization for osm and $c d 11 b$ and found a significant increase in osm mRNA in $c d 11 b^{+}$myeloid cells compared to non-myeloid cells

(Fig. 7c, e). To assess OSMR expression, we used immunohistochemistry and found increasing 
expression of OSMR in both Pdgfr- $\beta^{+}$fibroblasts and GFAP ${ }^{+}$astrocytes in the fibrotic and glial scar, respectively (Fig. 7d, f, g). Taken together, our results strongly suggest that the gp130 signaling pathway induced by Osm is a common mechanism by which astrocytes and fibroblasts are preferentially activated by specific monocyte/macrophage subtypes after SCl.

To identify other distinct and common pathways by which macrophage subtypes mediate astrogliosis and fibrosis, we calculated interaction scores for all known ligand-receptor pairs between Macrophage-A/B and astrocytes/fibroblasts at 3 and 7dpi (Fig. 8). While many ligands expressed by macrophages signaled to receptors on both astrocytes and fibroblasts (i.e. common pathways), there were many more ligand-receptor pairs unique to macrophage-fibroblast interactions than macrophage-astrocyte interactions (i.e. distinct pathways). These unique macrophage-fibroblast interactions included signaling related to IL $1 \alpha / \beta$, Vegfa/b, Pdgfa, and Tgf $\beta 1$. Overall, the highest interactions scores were associated with Spp1 and Apoe signaling, which were common to both astrocytes and fibroblasts. Macrophages also displayed subtype specificity in signaling to astrocytes and fibroblasts. For example, Jag1-Notch signaling was largely specific to Macrophage-A-astrocyte interaction, whereas IL $1 \alpha / \beta-I L 1 \mathrm{r} 1$ signaling was specific to Macrophage-B-fibroblast interaction. In summary, our analysis highlights the utility of our sc-RNAseq dataset in identifying potential signaling mechanisms that mediate astrogliosis and fibrosis after SCl.

\section{Discussion}

The overall goal of this study was to use sc-RNAseq to generate a resource with which we can gain insight into the complex cellular heterogeneity and interactions that occur at the spinal cord injury site. We were successful in isolating virtually every major cell type known to be present at the injury site, which provided an opportunity to assess the wound healing process with much less bias than prior studies that focused on single cell types. In this regard, we found that myeloid 
subtypes display distinct temporal regulation of angiogenesis, gliosis, and fibrosis. These results support previous studies showing that myeloid depletion leads to reduced angiogenesis, astrogliosis, and fibrosis after CNS injury ${ }^{3,27,28}$, and provide further insight by identifying potential contributions of specific myeloid subtypes.

We can begin to infer putative functions of the two macrophage subtypes by placing their temporal progression in context of prior studies. Our finding that Macrophage-A and B subtypes do not correspond to the M1/M2 nomenclature (Extended Data Fig. 5) is consistent with findings from other sc-RNAseq studies ${ }^{29-31}$. However, there are parallels with the generally accepted paradigm that macrophages shift from an anti-inflammatory to a more pro-inflammatory state over time after $\mathrm{SCl}^{32-34}$. As the major peripheral myeloid composition at the injury site shifts from monocytes to Macrophage-A and then to Macrophage-B over time, there is a progressive decrease in the classic anti-inflammatory enzyme Arginase 1 that is associated with increased pro-inflammatory IL1 and TNF pathways in Macrophage-B. Despite these pro-inflammatory functions, our data identified several mechanisms by which macrophages may have beneficial effects on the wound healing process. For example, Macrophage-B express Vegfa that is well-known to be necessary for growth and differentiation of endothelial cells during angiogenesis ${ }^{35}$. In addition, macrophages are a major source of osteopontin (spp1) and ApoE, both of which have neuroprotective roles after SCl. Spp1 and ApoE knockout mice both display worse histopathology and behavioral recovery after $\mathrm{SCl}$, whereas administration of ApoE mimetic improves recovery ${ }^{36-38}$. Thus, a future challenge is to limit the pro-inflammatory macrophage state without interfering with their beneficial effects on wound healing.

Of the microglial subtypes, DAM-D is notable for its expression profile defined by neuroprotective/neuroregenerative genes. In addition to osteopontin and ApoE whose protective roles were mentioned above, the well-known neuroprotective growth factor $\operatorname{lgf}-1^{39}$ was the best 
marker gene for DAM-D. Interestingly, a recent microglia depletion study demonstrated that microglia have a neuroprotective role by inducing astrogliosis via $\lg f-1^{28}$. This study also reported that scar-forming microglia that are located between the astroglial and fibrotic scars are the major source of Igf- 1 at $7 \mathrm{dpi}$, which is consistent with the appearance of DAM-D in our data, and suggests a spatial specificity for DAM-D. In addition, promoting proliferation of microglia reduced the lesion area and improved behavioral recovery, which supports the working model of dividing microglia giving rise to DAM-D. In addition to their neuroprotective effects, Igf-1 and osteopontin have been shown to promote axonal regeneration after $\mathrm{SCl}^{40-42}$, which make DAM-D an attractive therapeutic target for neurological disorders.

The vascular analysis revealed novel insight in the contribution of tip cells and astrocytes during angiogenesis after SCl. The data indicate that tip cells are highly dynamic; they appear quickly at $1 \mathrm{dpi}$ and are mostly gone by $7 \mathrm{pi}$. They are the major source of Angiopoietin-2, which destabilizes vessels, as well as placental growth factor, which promotes vessel formation, suggesting that tip cells mediate vessel remodeling during the few days after SCI. Interestingly, their disappearance overlaps with increased expression of Angiopoietin-1 in astrocytes. Angiopoietin-1 typically promotes vessel stabilization, suggesting that astrocytes contribute to vessel maturation after the initial phase of vascular remodeling by tip cells. This is corroborated by previous study demonstrating that when the blood-spinal cord barrier is restored by $21 \mathrm{dpi}$, blood vessels closely associated with astrocytes in the glial scar region express Glut1, whereas vessels in the astrocytedevoid fibrotic region do not express this mature blood-spinal cord barrier marker ${ }^{5}$. These data highlight an understudied role of astrogliosis in vessel maturation after $\mathrm{SCl}$, and provide new insight into prior astrocyte ablation studies that suggested "corralling" of infiltrating leukocytes by the astroglial scar ${ }^{25,43}$. Our data raise the possibility that reducing astrogliosis prevents maturation of blood vessels, which leads to increased infiltration of leukocytes into the spinal cord 
parenchyma surrounding the injury site. Other possible mechanisms of interactions between astrocytes, vasculature, and axons need to be explored in the future.

Our single cell RNA-seq dataset is the first comprehensive transcriptomic analysis that captures virtually all cells that contribute to the injury site pathology after SCI. This dataset can be used to assess not only heterogeneity of the cells that comprise the injury site, but also to assess signaling mechanisms that underlie cellular interactions at the injury site. Our own analysis revealed novel insight into myeloid cell heterogeneity, and specific signaling pathways by which unique myeloid subtypes contribute to the wound healing process, including angiogenesis and scar formation. These new insights can help decode the complex processes that underlie spinal cord injury pathobiology. 


\section{Acknowledgements}

Authors would like to thank the SCCC Onco-Genomics Shared Resource Core, Division of Veterinary Resources, DRI Flow Cytometry Core, HIHG Bioinformatics Core, Yan Shi at the Miami Project to Cure Paralysis Microscopy Core. Special thanks to Shaffiat Karmally and Yadira Salgueiro for their assistance in multiple aspects of this study, including animal care and logistics. This study was funded by NINDS R01NS081040 (J.K.L), University of Miami SAC Award UM SIP 2019-2 (J.K.L), NINDS F31NS115225 (C.B.R), the Miami Project to Cure Paralysis and The Buoniconti Fund, a generous gift from the Craig H. Nielsen Foundation, and NIH 1S10OD02357901 for the VS120 Slide Scanner housed at the University of Miami Miller School of Medicine Analytical Imaging Core Facility.

\section{Author Contributions}

L.M., J.S.C., J.K.L, C.B.R. designed and performed the experiments, analyzed the data, and wrote the manuscript. S.L.Y. performed the experiments and wrote the manuscript. P.T. designed the experiments, analyzed the data, and wrote the manuscript.

\section{Competing Interests}

The authors declare no competing interests. 


\section{Methods}

\section{Mice \& Spinal Cord Injuries}

For sequencing, flow cytometry, and histological validation of tip cells, C57BL/6J mice 8-10 weeks of age were purchased from Jackson Labs (Stock 000664). In total, we sequenced 2 biological replicates for each of the four time points to yield 8 sample datasets. For the first replicate at each time point, mice received spinal cord injury or no injury as described below and injury site (or corresponding region in uninjured controls) from each mice were individually processed for single cell RNA-seq (scRNA-seq). For the second replicate at each time point, we pooled cells from 2 animals using a modified tissue dissociation procedure as described below. For histological validation of activated fibroblasts, Postn-CreER mice (Jackson Laboratory stock 029645) were bred to Rosa26-EYFP mice (Jackson Laboratory stock 006148) to generate Postn ${ }^{\mathrm{EYFP}}$ mice. All mice were of C57BL/6 background. To induce EYFP expression, Postn ${ }^{\mathrm{EYFP}}$ mice were injected i.p (intraperitoneal) with $0.124 \mathrm{mg} / \mathrm{g}$ body weight of tamoxifen (MP Biomedicals, dissolved in 90\% sunflower oil, $10 \%$ ethanol) for 5 consecutive days. Contusive spinal cord injuries were performed 7 days after the last tamoxifen injection.

Contusive spinal cord injuries for all mice were performed as previously described ${ }^{3}$. Briefly, mice were anesthetized using ketamine/xylazine $(100 \mathrm{mg} / 15 \mathrm{mg} / \mathrm{kg}$ i.p.) and received a $65 \mathrm{kdyne}$ midthoracic (T8) contusion injury. Laminectomies were performed at the T8 vertebral level followed by stabilization via a spinal frame clamping the T7/T9 spinous processes. A computer controlled contusion injury was delivered using the Infinite Horizons Impactor device (Precision Systems and Instrumentation, LLC). Injured mice were given post-operative fluids subcutaneously consisting of Lactated Ringer's solution $(1 \mathrm{~mL})$, gentamycin $(5 \mathrm{mg} / \mathrm{kg})$ and buprenorphine $(0.05$ $\mathrm{mg} / \mathrm{kg}$ ) twice daily for 7 days. Bladders were manually expressed twice daily until the end of the experiment. All procedures were in accordance with University of Miami IACUC and NIH guidelines. 


\section{Tissue Dissociation}

Mice were anesthetized with Avertin (250mg/kg, i.p) before transcardial perfusion with artificial CSF solution $\left(87 \mathrm{mM} \mathrm{NaCl}^{2} 2.5 \mathrm{mM} \mathrm{KCl}, 1.25 \mathrm{mM} \mathrm{NaH}_{2} \mathrm{PO}_{4}, 26 \mathrm{mM} \mathrm{NaHCO}_{3}, 75 \mathrm{mM}\right.$ sucrose, $20 \mathrm{mM}$ glucose, $1.0 \mathrm{mM} \mathrm{CaCl}_{2}, 2 \mathrm{mM} \mathrm{MgSO}_{4}$ ). Solution was oxygenated on ice for $10 \mathrm{~min}$ before use. An $8 \mathrm{~mm}$ section of spinal cord centered at the injury site (or the corresponding location in uninjured tissue) was dissected. After removal of the meninges, tissue was chopped using a razor blade, washed with $5 \mathrm{~mL}$ CSF solution, and centrifuged at $300 \mathrm{~g}$ for $5 \mathrm{~min}$ at $4^{\circ} \mathrm{C}$. The pelleted cells were processed using the Miltenyi Neural Tissue Dissociation Kit (P) (Cat \#: 130-092-628) following manufacturer's suggested protocol to obtain a single cell suspension. In brief, the pellets were incubated in a $2 \mathrm{~mL}$ of Enzyme Mixture 1 for $30 \mathrm{~min}$ at $37^{\circ} \mathrm{C}(50 \mu \mathrm{L}$ Enzyme $\mathrm{P}$ in $1.9 \mathrm{~mL}$ Buffer $\mathrm{X})$ with gentle shaking by hand every 5 minutes. $30 \mu \mathrm{L}$ of Enzyme Mixture $2(10 \mu \mathrm{L}$ Enzyme A in $20 \mu \mathrm{L}$ Buffer $\mathrm{Y}$ ) was added to the cell suspensions and manually triturated (slowly, 10 times per sample) with a large (1000 $\mu$ m diameter) opening fire-polished pipette. After 10 min incubation at $37^{\circ} \mathrm{C}$, suspensions were triturated with a medium and then small $(750 \mu \mathrm{m}$ and $500 \mu \mathrm{m}$ diameter respectively) opening fire-polished pipette to produce single cell suspensions. Suspensions were strained through a $70 \mu \mathrm{M}$ cell strainer and washed with $10 \mathrm{~mL}$ CSF solution. Suspensions were centrifuged at $300 \mathrm{~g}$ for $5 \mathrm{~min}$ and supernatants were discarded. Cell pellets were incubated in $10 \mu \mathrm{l}$

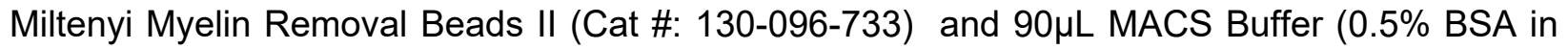
HBSS w/o Ca2+/Mg2+) for $15 \mathrm{~min}$ at $4^{\circ} \mathrm{C}$. Cells were washed with $10 \mathrm{~mL}$ MACS Buffer and centrifuged at $300 \mathrm{~g}$ for $5 \mathrm{~min}$. Supernatants were discarded and pellets were resuspended in 1 mL MACS buffer. Suspensions were then applied onto equilibrated LS Miltenyi MACS Magnetic Bead Columns (Cat \#: 130-042-401). Columns were washed with 2mL MACS buffer, flow through was centrifuged at $300 \mathrm{~g}$ for $5 \mathrm{~min}$, and supernatants were discarded. 
Due to the low number of astrocytes recovered in our first set of replicates, we enriched our second set of replicates with astrocytes by pooling from two spinal cord samples. We processed two spinal cords from each injury time point in parallel as described above to yield two suspensions per time point. One suspension from each time point was kept on ice while the was further processed with the Miltenyi Anti-ACSA-2 MicroBead kit according to manufacturer's instructions. In brief, suspensions were incubated with Miltenyi ACSA2 Beads for $15 \mathrm{mins}$ at $4^{\circ} \mathrm{C}$ and subsequently washed with $1 \mathrm{~mL}$ of MACS buffer. Suspensions were applied to LS Miltenyi MACS Magnetic Bead Columns and remaining cells were flushed from each column using LS Miltenyi column syringes and collected in separate tubes. ACSA-2 enriched flow throughs were then pooled with the single cell suspension from the other tissue.

Combined suspensions were centrifuged at $300 \mathrm{~g}$ for $5 \mathrm{~min}$ and the pellets were resuspended in Red Blood Cell Lysis buffer (155 $\mathrm{mM} \mathrm{NH}_{4} \mathrm{Cl}, 10 \mathrm{mM} \mathrm{KHCO}_{3}, 0.09 \mathrm{mM}$ Na4-EDTA) and incubated at room temperature for $1 \mathrm{~min}$. After washing with $5 \mathrm{~mL}$ MACS Buffer, suspensions were centrifuged at $300 \mathrm{~g}$ for $5 \mathrm{~min}$ and supernatants were discarded. Pellets were resuspended in $50 \mu$ FACS buffer (1\% BSA + 0.05\% sodium azide in HBSS w/o Ca2+/Mg2+) and processed for scRNA-seq. Before submitting for sequencing, each sample underwent a quality control assessment which included cell viability and number. Briefly, cell suspensions were incubated with ViaStain AOPI Staining Solution and cell concentration/viability was assessed using the Nexcelom Cellometer K2. Each submitted sample met a viability cutoff of $80 \%$ or higher. Each sample was diluted accordingly to achieve a target cell capture of 10,000 cells, with our actual capture for the two replicates totaling 4721 for Uninjured, 14536 for $1 \mathrm{dpi}, 19405$ for 3dpi, and 18446 for $7 \mathrm{dpi}$.

\section{Histology}


Mice were anesthetized with Avertin as described above and transcardially perfused with cold $4 \%$ paraformaldehyde (PFA) in PBS. Spinal cord was removed, and following 2 hours of post-fixation in 4\% PFA, it was placed in $30 \%$ sucrose (in PBS) solution overnight on a shaker. $8 \mathrm{~mm}$ segment of the spinal cord centered at the injury site (or the corresponding region in uninjured spinal cord) was embedded in OCT compound (Tissue-Tek) and sectioned sagittally on a cryostat (16 $\mu \mathrm{m})$. Serial tissue sections were mounted onto Superfrost Plus slides, and was stored at $-20^{\circ} \mathrm{C}$.

\section{Immunohistochemistry}

After drying at room temperature, tissue sections were washed once with PBS, followed by permeabilization with PBS-T for 10 min at RT (0.3\% Triton X-100 in PBS). After $1 \mathrm{hr}$ of incubation in blocking solution at room temperature ( $5 \%$ normal donkey serum in PBS-T), sections were incubated in primary antibody diluted in $5 \%$ normal donkey serum overnight at $4^{\circ} \mathrm{C}$ (primary antibodies are listed in the table below). After primary antibody incubation, slides were washed 2 times with PBS for 2 min each. Slides were incubated with appropriate AlexaFluor secondary antibodies (1:500 in PBS-T) for $1 \mathrm{hr}$ at room temperature. Slides were washed with 2 times PBS for 2 min each and incubated with DAPI $(1: 15,000)$ for $3 \mathrm{~min}$ at room temperature in the dark. Slides were washed with PBS and glass coverslips were mounted with Fluoromount-G (Southern Biotech Cat \#: 0100-01). Images were taken on an Olympus Fluoview1000 Confocal Microscope or on an Olympus VSI Slide Scanner.

\begin{tabular}{|l|l|l|l|}
\hline Antibody & Company & Catalog \#/RRID & Dilution \\
\hline Chicken anti-GFAP & Abcam & ab4674/AB-304558 & $1: 500$ \\
\hline Rat anti-GFAP & Life Technologies & $13-0300 / A B-86543$ & $1: 500$ \\
\hline Rabbit anti-PDGFR (Y92) & Abcam & ab32570/AB-777165 & $1: 200$ \\
\hline Goat anti-OSMR & R\&D Systems & AF-662-SP/AB-355511 & $1: 100$ \\
\hline Goat anti-Podocalyxin & R\&D Systems & AF1556/AB-354858 & $1: 200$ \\
\hline
\end{tabular}




\section{$\underline{\text { In situ hybridization }}$}

Tissue sections were prepared as described above. In situ hybridization was performed using the RNAscope Multiplex Fluorescent Kit v2 (Advanced Cell Diagnostics Cat \#: 323100) with a few modifications to the manufacturer's protocol. All incubations were at room temperature unless otherwise noted. Briefly, slides were incubated in hydrogen peroxide for $10 \mathrm{~min}$. After washing with distilled water, slides were incubated in $1 \mathrm{X}$ Target Retrieval Solution at $95^{\circ} \mathrm{C}$ for $1 \mathrm{~min}$. After washing with distilled water, slides were incubated in $100 \% \mathrm{EtOH}$ for $3 \mathrm{~min}$. Slides were left to dry before incubation in RNAscope Protease III solution at $40^{\circ} \mathrm{C}$ for $30 \mathrm{~min}$ (all $40^{\circ} \mathrm{C}$ incubations were in the Advanced Cell Diagnostics HybEZ Oven). After incubation, slides were washed with distilled water and incubated in probe solution for $2 \mathrm{hrs}$ at $40^{\circ} \mathrm{C}$. The following probes were purchased from Advanced Cell Diagnostics: C2 Mm-OSM (Cat \#: 427071-C2 (1:50)), C1 Mm-ITGAM (Cat \#: 311491 (no dilution, used working solution)), C2 Mm-Apln (Cat \#: 415371-C2 (1:50)). Following probe hybridization, each amplifier was individually incubated with slides for $30 \mathrm{~min}$ at $40^{\circ} \mathrm{C}$. Before each fluorophore incubation, slides were incubated in RNAscope HRP solution for 15min at $40^{\circ} \mathrm{C}$. Fluorophores for each channel were prepared at 1:750 in RNAscope Diluent Solution, and individually incubated with slides for $30 \mathrm{~min}$ at $40^{\circ} \mathrm{C}$. Different combinations of TSA Plus Cyanine 5 (Perkin Elmer Cat \#: NEL745001KT) and TSA Plus Fluorescein (Perkin Elmer Cat \#: NEL74100KT) were used with different probe channels. After each individual fluorophore incubation, slides were washed with RNAscope 1X Wash Buffer and incubated with RNAscope HRP Blocker solution for $15 \mathrm{~min}$ at $40^{\circ} \mathrm{C}$. After in situ hybridization, slides were washed with PBS and immunohistochemically stained with appropriate primary antibodies as described above.

\section{Tissue Quantifications}

For each sagittal tissue section of the OSMR/GFAP/PDGFR- $\beta$ and OSM/GFAP/CD11b stain (immunohistochemistry and in situ hybridization, respectively), three $40 \mathrm{X}$ confocal images were 
taken surrounding the injury site ( 3 serial tissue sections were analyzed per animal). Images were analyzed using the Cellomics High-Content Screening software. To quantify total signal colocalization between GFAP/PDGFR- $\beta$ and OSMR, we used the Target Activation V3 algorithm, with a minimum intensity threshold set to 350 for OSMR fluorescence. To count the number of OSM+/CD11b+ nuclei within the injury site, we used the Colocalization V4 algorithm.

\section{Flow Cytometry}

Mice received spinal cord injury as described above, and injury sites were processed for flow cytometry. Mice were anesthetized with Avertin followed by transcardial perfusion with ice-cold PBS. An $8 \mathrm{~mm}$ segment of the spinal cord centered at the injury site was dissected and the meningeal layer was removed. Spinal cords were manually dissociated by mechanical grinding against a $70 \mu \mathrm{m}$ cell strainer (the plunger of a $3 \mathrm{~mL}$ syringe was used for mechanical dissociation). Strainers were washed with $10 \mathrm{~mL}$ HBSS (w/o Ca2+/Mg2+) and centrifuged at $300 \mathrm{~g}$ for $10 \mathrm{~min}$. Supernatant was aspirated and the pellet was resuspended in $10 \mu \mathrm{L}$ Miltenyi Myelin Removal Beads II (Miltenyi Biotec Cat \#: 130-096-733) and $90 \mu \mathrm{L}$ MACS Buffer (0.5\% BSA in HBSS w/o $\mathrm{Ca} 2+/ \mathrm{Mg} 2+)$ and incubated for $15 \mathrm{~min}$ at $4^{\circ} \mathrm{C}$. Cells were washed with $10 \mathrm{~mL}$ MACS Buffer and centrifuged at $300 \mathrm{~g}$ for $10 \mathrm{~min}$. Pellet was resuspended in $1 \mathrm{~mL}$ MACS buffer and applied onto equilibrated LS Miltenyi MACS Magnetic Bead Columns (Miltenyi Biotec Cat \#: 130-042-401). Columns were washed with $2 \mathrm{~mL}$ MACS buffer and suspension was centrifuged at $300 \mathrm{~g}$ for $5 \mathrm{~min}$. Pellet was resuspended in RBC Lysis buffer (155mM NH${ }_{4} \mathrm{Cl}, 10 \mathrm{mM} \mathrm{KHCO}_{3}, 0.09 \mathrm{mM}$ Na4-EDTA) and kept at room temperature for $1 \mathrm{~min}$. To identify live cells, pellet was resuspended in Zombie Aqua Viability Dye and incubated for 30min at room temperature (Biolegend Cat \#: 423101). Following a wash in PBS and spin at 300g, cells were resuspended in Fix/Perm Solution for 20min at $4^{\circ} \mathrm{C}$ to fix and permeabilize the cells (BD Bioscience Cytofix/Cytoperm Cat \#: 554714). After incubation, cells were washed with $1 \mathrm{~mL}$ of Perm/Wash solution. After centrifugation at $300 \mathrm{~g}$ for $10 \mathrm{~min}$, supernatant was aspirated and the cells were incubated in blocking buffer mixture for $5 \mathrm{~min}$ 
at $4^{\circ} \mathrm{C}$ (1uL anti-mouse CD16/32 TruStain Fcx (RRID: AB-1877271 AB-1574973, Biolegend Cat \#: 101320) and 99uL FACS buffer (1\% BSA + 0.05\% sodium azide in HBSS w/o Ca2+/Mg2+)). Antibody mixture was added directly to the cell suspension and incubated for $20 \mathrm{~min}$ at $4^{\circ} \mathrm{C}$. Cells were washed with $5 \mathrm{~mL}$ FACS buffer and centrifuged at $300 \mathrm{~g}$ for $10 \mathrm{~min}$. For fixation, cells were resuspended in $4 \%$ PFA and incubated for $30 \mathrm{~min}$ at $4^{\circ} \mathrm{C}$. After centrifugation at $300 \mathrm{~g}$ for $10 \mathrm{~min}$, cells were resuspended in $250 \mu \mathrm{L}$ FACS buffer and transferred into a flat bottom 96-well plate. 10 $\mathrm{LL}$ of 123 eBeads Counting Beads (ThermoFischer Scientific Cat \#: 01-1234-42) were added to each sample well and cells were kept at $4^{\circ} \mathrm{C}$ until analysis on a Cytoflex Flow Cytometer (Beckman Coulter).

Macrophage Flow Antibody Panel:

\begin{tabular}{|l|l|l|l|}
\hline Antibody & Company & Catalog \#/RRID & Dilution \\
\hline CD16/32 TruStain Fcx & Biolegend & $101320 / A B-1574975$ & $1: 100$ \\
\hline Zombie Aqua Viability Dye & Biolegend & $423101 /$ NA & $1: 2.5$ \\
\hline CD45.2 (APC-Cy7)_ & Biolegend & $103116 / 312981$ & $1: 200$ \\
\hline CD11b (APC) & Biolegend & $101212 / 312795$ & $1: 200$ \\
\hline Ly6G (PerCP Cy5.5) & Biolegend & $127616 / A B-1877271$ & $1: 200$ \\
\hline CD63 (PE/Dazzle 594) & Biolegend & $143913 / 2565503$ & $1: 100$ \\
\hline ApoE (Dylight 680) & Novus Biologicals & NB110-60531FR/NA & $1: 100$ \\
\hline
\end{tabular}

Microglia Flow Antibody Panel:

\begin{tabular}{|l|l|l|l|}
\hline Antibody & Company & Catalog \#/RRID & Dilution \\
\hline CD16/32 TruStain Fcx & Biolegend & $101320 / A B-1877271$ & $1: 100$ \\
\hline Zombie Aqua Dye & Biolegend & $423101 /$ NA & $1: 2.5$ \\
\hline CD45.2 (APC-Cy7) & Biolegend & $103116 / 312981$ & $1: 200$ \\
\hline
\end{tabular}




\begin{tabular}{|l|l|l|l|}
\hline CD11b (APC) & Biolegend & $101212 / 312795$ & $1: 200$ \\
\hline Ly6G (PerCP Cy5.5) & Biolegend & $127616 / A B-1877271$ & $1: 200$ \\
\hline P2ry12 (PE) & Biolegend & $848003 / 2721644$ & $1: 100$ \\
\hline MSR1 (Alexa-Fluor 700) & BioRad & MCA1322A700/2251086 & $1: 50$ \\
\hline
\end{tabular}

\section{Single Cell Sequencing \& Bioinformatics}

\begin{tabular}{|c|c|c|}
\hline Software, Algorithms, and Data & Source & Version \\
\hline CellRanger & 10X Genomics & 2.2.0 and 3.0.1 \\
\hline RStudio & Rstudio, Inc. & 1.2 .5001 \\
\hline $\mathrm{R}$ & The R Foundation & 3.6 .1 \\
\hline Seurat & https://satijalab.org/seurat/ & 3.1 .2 \\
\hline ggplot2 & Wickham H (2016) ${ }^{44}$ & 3.3 .0 \\
\hline dplyr & Wickham H et al. (2020) & 0.8 .5 \\
\hline scater & McCarthy et al (2017) ${ }^{45}$ & 1.12 .2 \\
\hline DropletUtils & Lun et al. $(2019)^{46}$ & 1.4 .3 \\
\hline python & Python Software Foundation & 3.7 .6 \\
\hline Scrublet & Wolock et al. (2019) ${ }^{47}$ & 0.2 .1 \\
\hline topGO & Rahnenfuhrer J (2020) ${ }^{48}$ & 2.4 .0 \\
\hline biomaRt & Durinck et al (2009) ${ }^{49}$ & 2.40 .5 \\
\hline $\begin{array}{l}\text { scRNA-seq for Mouse Nervous } \\
\text { System }\end{array}$ & Zeisel et al. $(2018)^{50}$ & http://mousebrain.org/ \\
\hline Ligand-Receptor pair database & Ramiloski et al $(2015)^{51}$ & $\begin{array}{l}\text { https://fantom.gsc.riken.jp } \\
\text { /5/suppl/Ramilowski_et_al } \\
\text { _2015/ }\end{array}$ \\
\hline
\end{tabular}

\section{Single cell RNA-sequencing using 10X Genomics platform}

Single-cell suspensions were prepared as described above. Two biological replicates for each time point for a total of 8 samples were sequenced with a median of $\sim 8000$ cells per sample. The 
median of mean reads per cell across samples was $>55,000$ and median sequencing saturation was $81.2 \%$. Libraries for all samples were prepared according to Chromium Single Cell 3' Library and Gel Bead Kit v2 instructions (10X Genomics, PN-120237) and indexed with Chromium i7 Multiplex Kits (10X Genomics, PN-120262). In brief, each cell suspension was first partitioned into single-cell gel beads-in-emulsion (GEMs) and then incubated with reverse-transcriptase primers and reaction mix. Primers contain i) a 16nt 10X barcode, ii) a 10nt Unique Molecular Identifier, iii) a poly-dT primer sequence, and iv) an Illumina Read 1 (R1) sequence to produce single-stranded, barcoded complementary DNA (cDNA) from poly-adenylated mRNA. After breaking GEMs to recover cDNA fractions, leftover biochemical reagent was removed with Silane Dynabeads (10X Genomics, PN-2000048), and pooled fractions were amplified via PCR to generate full-length, double-stranded, barcoded cDNA. Products were then enzymatically fragmented, end repaired, and modified with dA-tails. Insert sizes were filtered with double-sided size selection using SPRIselect (Beckman Coulter, B23318) before cDNA molecules were ligated to Illumina Read 2 (R2) adapters. To construct final libraries for Illumina sequencing, P5, P7, and sample index sequences were inserted into molecules by sample index PCR and then amplified. For sequencing, libraries were loaded at recommended loading concentrations onto an Illumina NextSeq 500 flow cell and paired-end sequenced under recommended settings (R1: 28 cycles; i7 index: 8 cycles; i5 index: none; R2: 91 cycles). After sequencing, Illumina output was processed using CellRanger's recommended pipeline to generate gene-barcode count matrices. In brief, base call files for each sample were demultiplexed into FASTQ reads and then aligned to the mouse mm10 reference genome using STAR splice-aware aligner. Reads that confidently intersected at least $50 \%$ with an exon were considered exonic and further aligned with annotated transcripts. Reads were then filtered to remove UMls and barcodes with single base substitution errors and finally used for UMI counting. The output was a count matrix containing all UMI counts for every droplet. CellRanger v2.2.0 was used for the first set of replicates and v3.0.1 for the second set of replicates. 


\section{Preprocessing and Quality Control}

To distinguish cell-containing droplets from empty droplets, we performed cell calling on the unfiltered UMI count matrices using a combination of barcode-ranking and empty-droplet detection algorithms. First, cell barcodes were ranked according to UMI count and visualized in a log-total UMI count vs log-rank plot. A spline curve was fit to the data to identify knee and inflection points. At least all data points above the knee were considered cell-containing droplets. In order to further distinguish cells from data below the knee, we used the emptyDrops function from the DropletUtils $\mathrm{R}$ package ${ }^{52}$ using the following fixed parameters for all sample: lower = 250; $\max$ fit. bounds $=1 \mathrm{e} 06 ; \mathrm{FDR}=0.001 ;$ ignore $=10$. Some parameters varied between samples accordingly: "retain" was set to knee point values, and "lower" was set to inflection point values. The result was a filtered count matrix of all putative cell-containing droplets. In order to distinguish low quality cells, we considered cell-level metrics such as library size, percentage of UMls mapping to mitochondrial genes, and doublet detection algorithm outputs. We observed that removing cells in the lowest quantiles of total UMI counts preferentially selected against endothelial cells, while removing cells in the highest quantiles of mitochondrial percentage preferentially selected against astrocytes. To avoid bias due to any one metric, we used a multivariate approach to automatic outlier detection as implemented in the Scater R package ${ }^{45}$, which performs principal component analysis on the quality control metrics to determine outliers.

In order to remove potential doublets, we applied the Scrublet Python package ${ }^{47}$ for each individual sample. In brief, the Scrublet simulates multiplets by sampling from the data and builds a nearest-neighbor classifier. Cells from the data that have high local densities of simulated doublets are flagged and removed. We set the expected_doublet_rate for each sample according to the estimated doublet rate per cells sequenced as published by $10 \mathrm{X}$, and default values for all other parameters. During downstream analysis, we observed small, unidentifiable clusters that 
co-expressed marker genes for two different cell-types, and removed these cells as they were likely to be multiplets not detected by Scrublet. Additionally, we identified a cluster enriched for hemoglobin genes (Hbb-bs, Hbb-bt, etc.) which was removed from downstream analyses.

\section{Normalization and Batch Correction}

To generate the full SCl dataset, all samples were processed and combined using Seurat v ${ }^{53}$. After filtering each sample count matrix for genes that were expressed in at least 10 cells, each dataset was independently normalized and scaled using the SCTransform function. SCTransform performs a variance-stabilizing transformation in which genes are grouped according to mean expression in order to smoothen model parameters for negative binomial regression ${ }^{54}$. To remove cell-cycle genes as a confounding source of variation, mitochondrial percentage and cell cycle scores based on the expression of canonical G2M and S phase markers were computed for each cell. Cell cycle genes were provided through the Seurat tutorial. These score values were then used as input for the "vars.to.regress" argument in the SCTransfrom() function. This operation generates a "corrected" expression matrix by building a regression model on these variables for each gene. To identify shared and unique molecular cell-types across datasets and time-points, sample expression matrices were batch-corrected using Seurat's Data Integration workflow ${ }^{55}$. In brief, data integration uses canonical correlation analysis between two samples to identify mutual nearest neighbors. These "anchors" are then used to generate a corrected gene expression matrix based on the consistency of the anchors between cells, effectively performing a batch correction. For the full SCl dataset, the 2000 most variables genes were used as input for the "anchor.features" argument of the FindlntegrationAnchors() function, where the variance of a gene was measured as the residual divided by the expected variance under the SCTransfrom() model. This resulted in a single, batch-corrected expression matrix for containing all cells. 
For the analysis of the myeloid cells, we tested a similar batch correction as described above. However, we observed that some microglia from the uninjured spinal cord were classified under a peripheral macrophage subset but not under BA-Macrophage (data not shown). We attributed this potential misclassification to the imbalance between uninjured and injured cell counts, and the large proportion of peripheral myeloid cells in the injured samples. We instead combined sample datasets across time-points for each replicate and subsequently performed normalization for each of the two larger datasets as above (i.e. normalize across times and batch-correct across replicates). For myeloid integration, the 2000 most variable genes were used. For the vascular cells, no obvious misclassifications were noted. We proceeded with normalization and batch correction as above, using the 2000 most variable genes for downstream analysis. For the macroglia cells, we again observe no obvious misclassifications and proceeded with normalization and batch correction. However because of the low numbers of macroglia cells in one of the uninjured sample replicates, we adjusted the "k.filter" parameter to 100 for the FindlntegrationAnchors() function.

\section{Dimensional Reduction, Clustering, and Differential Gene expression testing}

In order to measure the greatest gene expression variation among all the $\mathrm{SCl}$ cells, we first performed PCA on the batch-corrected expression matrix for the top 2000 variable genes taken from above. The top 15 principal components (PCs) were selected based on the "elbow" point heuristic in a scree plot which quantifies the contribution of variance by each principal component. Using these components, a nearest-neighbor graph and shared-nearest-neighbor graph were generated with "k.neighbors" set to 20 by default. To visualize the cells, we generate a UMAP plot with default Seurat parameters using cell coordinates in PCA-space using the top 15 PCs. In order to cluster the cells based on similarity of expression, we ran the FindClusters() function on the shared-nearest-neighbor graph with default parameters. 
For the myeloid, vascular, and macroglial cells, we performed similar analyses as described above, with a few modifications. In order to identify reproducible sub-clusters of cells, we performed the same graph-based clustering through a range of PCs, "k.neighbor" and "resolution" parameters and inspected cluster memberships for stable configurations. For the myeloid, vascular, and macroglia, we took the top 12,11 , and 8 PCs and set resolutions to $0.5,0.3$, and 0.45 respectively. To identify marker genes for each cluster, we used the FindAllMarkers() function using default parameters, which implements a Wilcoxon Rank Sum test comparing gene expression of cells within a given cluster versus all other cells. We repeated this analysis to identify marker genes distinguishing subsets within a cell-type.

To infer the functional relevance of sub-clusters, we performed gene ontology enrichment analyses on the top 50 differentially expressed genes using Fisher's Exact test as implemented in the topGO $\mathrm{R}$ package ${ }^{48}$. For the enrichment analyses of the gene expression changes in astrocytes, our initial analysis revealed very few differentially expressed genes between the uninjured and $1 \mathrm{dpi}$ astrocytes, which we attributed to the low numbers of uninjured astrocytes captured. Therefore, we supplemented our uninjured astrocyte dataset with ACNT1 and ACNT2 astrocyte data from the previously published mouse CNS single-cell atlas dataset ${ }^{50}$. We also supplemented our uninjured OPC dataset in order to validate that our uninjured cells were more transcriptional similar to the external reference cells than to our injured cells. To account for differences in sequencing depth between our dataset and the external dataset, we performed differential expression tests using MAST as implemented in Seurat ${ }^{56}$. We used all differentially expressed genes (p_val_adj < 0.001) as input for gene ontology analysis.

\section{Ligand-Receptor Interaction Analysis}

To infer potential ligand-receptor interactions between two cell-types, we adapted the method used in CellPhoneDB ${ }^{15}$. We first pulled a reference list of human ligand-receptor pairs published 
previously ${ }^{51}$ and converted the genes into mouse orthologs using the Ensembl biomaRt package ${ }^{49}$. We defined the ligand-receptor score as the mean of the average log-normalized expression of the receptor gene in one cell-type and the average log-normalized expression of the ligand gene in a second cell-type. To identify enriched ligand-receptor interactions, we applied a permutation test to identify interactions scores that are enriched in a specific <ligand cell $A$, receptor cell B, time-point> combination. For each of 1000 permutations, we randomly shuffled the cell-type and time-point labels and calculated an interaction scores for all possible <ligand cell, receptor cell, time-point> combinations. Repeating this 1000 times generated a null distribution of interaction scores for each ligand-receptor pair. We compared the interaction scores of the actual (ligand cell A, receptor cell B, time-point) labels to the null distribution and calculated p-values as the proportion of null scores which are equal to or greater than the actual interaction score. 


\section{References:}

1. Milich, L.M., Ryan, C.B. \& Lee, J.K. The origin, fate, and contribution of macrophages to spinal cord injury pathology. Acta Neuropathol 137, 785-797 (2019).

2. Barnabe-Heider, F., et al. Origin of new glial cells in intact and injured adult spinal cord. Cell Stem Cell 7, 470-482 (2010).

3. Zhu, Y., et al. Hematogenous macrophage depletion reduces the fibrotic scar and increases axonal growth after spinal cord injury. Neurobiology of disease 74, 114-125 (2015).

4. Herrmann, J.E., et al. STAT3 is a critical regulator of astrogliosis and scar formation after spinal cord injury. The Journal of neuroscience : the official journal of the Society for Neuroscience 28, 7231-7243 (2008).

5. Whetstone, W.D., Hsu, J.Y., Eisenberg, M., Werb, Z. \& Noble-Haeusslein, L.J. Bloodspinal cord barrier after spinal cord injury: relation to revascularization and wound healing. $J$ Neurosci Res 74, 227-239 (2003).

6. Baldwin, S.A., Broderick, R., Blades, D.A. \& Scheff, S.W. Alterations in temporal/spatial distribution of GFAP- and vimentin-positive astrocytes after spinal cord contusion with the New York University spinal cord injury device. J Neurotrauma 15, 1015-1026 (1998).

7. Soderblom, C., et al. Perivascular fibroblasts form the fibrotic scar after contusive spinal cord injury. The Journal of neuroscience : the official journal of the Society for Neuroscience 33, 13882-13887 (2013).

8. Sanz, E., et al. Cell-type-specific isolation of ribosome-associated mRNA from complex tissues. Proceedings of the National Academy of Sciences of the United States of America 106, 13939-13944 (2009).

9. Heiman, M., et al. A translational profiling approach for the molecular characterization of CNS cell types. Cell 135, 738-748 (2008).

10. Ankeny, D.P. \& Popovich, P.G. Mechanisms and implications of adaptive immune responses after traumatic spinal cord injury. Neuroscience 158, 1112-1121 (2009).

11. Keren-Shaul, $\mathrm{H}$., et al. A Unique Microglia Type Associated with Restricting Development of Alzheimer's Disease. Cell 169, 1276-1290.e1217 (2017).

12. Murray, P.J. Macrophage Polarization. Annu Rev Physiol 79, 541-566 (2017).

13. Vanlandewijck, M., et al. A molecular atlas of cell types and zonation in the brain vasculature. Nature 554, 475-480 (2018).

14. Reaux, A., Gallatz, K., Palkovits, M. \& Llorens-Cortes, C. Distribution of apelinsynthesizing neurons in the adult rat brain. Neuroscience 113, 653-662 (2002).

15. Vento-Tormo, R., et al. Single-cell reconstruction of the early maternal-fetal interface in humans. Nature 563, 347-353 (2018).

16. Eklund, L., Kangas, J. \& Saharinen, P. Angiopoietin-Tie signalling in the cardiovascular and lymphatic systems. Clin Sci (Lond) 131, 87-103 (2017).

17. Gerhardt, H., et al. VEGF guides angiogenic sprouting utilizing endothelial tip cell filopodia. The Journal of cell biology 161, 1163-1177 (2003).

18. Reinert, R.B., et al. Vascular endothelial growth factor coordinates islet innervation via vascular scaffolding. Development (Cambridge, England) 141, 1480-1491 (2014).

19. Apte, R.S., Chen, D.S. \& Ferrara, N. VEGF in Signaling and Disease: Beyond Discovery and Development. Cell 176, 1248-1264 (2019).

20. Nagy, J.A., Dvorak, A.M. \& Dvorak, H.F. VEGF-A(164/165) and PIGF: roles in angiogenesis and arteriogenesis. Trends in cardiovascular medicine 13, 169-175 (2003).

21. Ribatti, D. The discovery of the placental growth factor and its role in angiogenesis: a historical review. Angiogenesis 11, 215-221 (2008).

22. Hackett, A.R., et al. STAT3 and SOCS3 regulate NG2 cell proliferation and differentiation after contusive spinal cord injury. Neurobiology of disease 89, 10-22 (2016). 
23. Hackett, A.R. \& Lee, J.K. Understanding the NG2 Glial Scar after Spinal Cord Injury. Front Neurol 7, 199 (2016).

24. Anderson, M.A., et al. Astrocyte scar formation aids central nervous system axon regeneration. Nature 532, 195-200 (2016).

25. Wanner, I.B., et al. Glial scar borders are formed by newly proliferated, elongated astrocytes that interact to corral inflammatory and fibrotic cells via STAT3-dependent mechanisms after spinal cord injury. The Journal of neuroscience : the official journal of the Society for Neuroscience 33, 12870-12886 (2013).

26. Bonni, A., et al. Regulation of gliogenesis in the central nervous system by the JAKSTAT signaling pathway. Science (New York, N.Y.) 278, 477-483 (1997).

27. Amankulor, N.M., et al. Sonic hedgehog pathway activation is induced by acute brain injury and regulated by injury-related inflammation. The Journal of neuroscience : the official journal of the Society for Neuroscience 29, 10299-10308 (2009).

28. Bellver-Landete, $\mathrm{V}$., et al. Microglia are an essential component of the neuroprotective scar that forms after spinal cord injury. Nat Commun 10, 518 (2019).

29. Ydens, E., et al. Profiling peripheral nerve macrophages reveals two macrophage subsets with distinct localization, transcriptome and response to injury. Nature neuroscience (2020).

30. Lin, J.D., et al. Single-cell analysis of fate-mapped macrophages reveals heterogeneity, including stem-like properties, during atherosclerosis progression and regression. JCI Insight 4 (2019).

31. Muller, S., et al. Single-cell profiling of human gliomas reveals macrophage ontogeny as a basis for regional differences in macrophage activation in the tumor microenvironment. Genome biology 18, 234 (2017).

32. Kigerl, K.A., et al. Identification of two distinct macrophage subsets with divergent effects causing either neurotoxicity or regeneration in the injured mouse spinal cord. The Journal of neuroscience : the official journal of the Society for Neuroscience 29, 13435-13444 (2009).

33. Wang, $\mathrm{X}$., et al. Macrophages in spinal cord injury: phenotypic and functional change from exposure to myelin debris. Glia 63, 635-651 (2015).

34. Kroner, A., et al. TNF and increased intracellular iron alter macrophage polarization to a detrimental M1 phenotype in the injured spinal cord. Neuron 83, 1098-1116 (2014).

35. Neufeld, G., Cohen, T., Gengrinovitch, S. \& Poltorak, Z. Vascular endothelial growth factor (VEGF) and its receptors. FASEB J 13, 9-22 (1999).

36. Hashimoto, M., Sun, D., Rittling, S.R., Denhardt, D.T. \& Young, W. Osteopontin-deficient mice exhibit less inflammation, greater tissue damage, and impaired locomotor recovery from spinal cord injury compared with wild-type controls. The Journal of neuroscience : the official journal of the Society for Neuroscience 27, 3603-3611 (2007).

37. Yang, X., et al. Apolipoprotein E Deficiency Exacerbates Spinal Cord Injury in Mice: Inflammatory Response and Oxidative Stress Mediated by NF-kappaB Signaling Pathway. Front Cell Neurosci 12, 142 (2018).

38. Wang, R., et al. ApoE mimetic ameliorates motor deficit and tissue damage in rat spinal cord injury. J Neurosci Res 92, 884-892 (2014).

39. Guan, J., et al. The role for IGF-1-derived small neuropeptides as a therapeutic target for neurological disorders. Expert Opin Ther Targets 19, 785-793 (2015).

40. Ozdinler, P.H. \& Macklis, J.D. IGF-I specifically enhances axon outgrowth of corticospinal motor neurons. Nature neuroscience 9, 1371-1381 (2006).

41. Liu, Y., et al. A Sensitized IGF1 Treatment Restores Corticospinal Axon-Dependent Functions. Neuron 95, 817-833 e814 (2017).

42. Anderson, M.A., et al. Required growth facilitators propel axon regeneration across complete spinal cord injury. Nature 561, 396-400 (2018). 
43. Faulkner, J.R., et al. Reactive astrocytes protect tissue and preserve function after spinal cord injury. The Journal of neuroscience : the official journal of the Society for Neuroscience 24, 2143-2155 (2004).

44. Hadley, W. Ggplot2 (Springer Science+Business Media, LLC, New York, NY, 2016).

45. McCarthy, D.J., Campbell, K.R., Lun, A.T. \& Wills, Q.F. Scater: pre-processing, quality control, normalization and visualization of single-cell RNA-seq data in R. Bioinformatics 33, 1179-1186 (2017).

46. Lun, A.T.L., et al. EmptyDrops: distinguishing cells from empty droplets in droplet-based single-cell RNA sequencing data. Genome biology 20, 63 (2019).

47. Wolock, S.L., Lopez, R. \& Klein, A.M. Scrublet: Computational Identification of Cell Doublets in Single-Cell Transcriptomic Data. Cell Syst 8, 281-291 e289 (2019).

48. Rahnenfuhrer, A.A. topGO: Enrichment Analysis for Gene Ontology. in $R$ package (2020).

49. Durinck, S., Spellman, P.T., Birney, E. \& Huber, W. Mapping identifiers for the integration of genomic datasets with the R/Bioconductor package biomaRt. Nat Protoc 4, 11841191 (2009).

50. Zeisel, A., et al. Molecular Architecture of the Mouse Nervous System. Cell 174, 9991014 e1022 (2018).

51. Ramilowski, J.A., et al. A draft network of ligand-receptor-mediated multicellular signalling in human. Nat Commun 6, 7866 (2015).

52. Lun, A.T.L., et al. EmptyDrops: distinguishing cells from empty droplets in droplet-based single-cell RNA sequencing data. Genome biology 20, 63 (2019).

53. Stuart, T., et al. Comprehensive Integration of Single-Cell Data. Cell 177, 18881902.e1821 (2019).

54. Hafemeister, C. \& Satija, R. Normalization and variance stabilization of single-cell RNAseq data using regularized negative binomial regression. Genome biology 20, 296 (2019).

55. Butler, A., Hoffman, P., Smibert, P., Papalexi, E. \& Satija, R. Integrating single-cell transcriptomic data across different conditions, technologies, and species. Nature biotechnology 36, 411-420 (2018).

56. Finak, G., et al. MAST: a flexible statistical framework for assessing transcriptional changes and characterizing heterogeneity in single-cell RNA sequencing data. Genome biology 16, 278 (2015). 
bioRxiv preprint doi: https://doi.org/10.1101/2020.05.13.094854; this version posted May 14,2020 . The copyright holder for this preprint (which was not certified by peer review) is the author/funder, who has granted bioRxiv a license to display the preprint in perpetuity. It is made available under ACC-BY-NC-ND 4.0 International license.

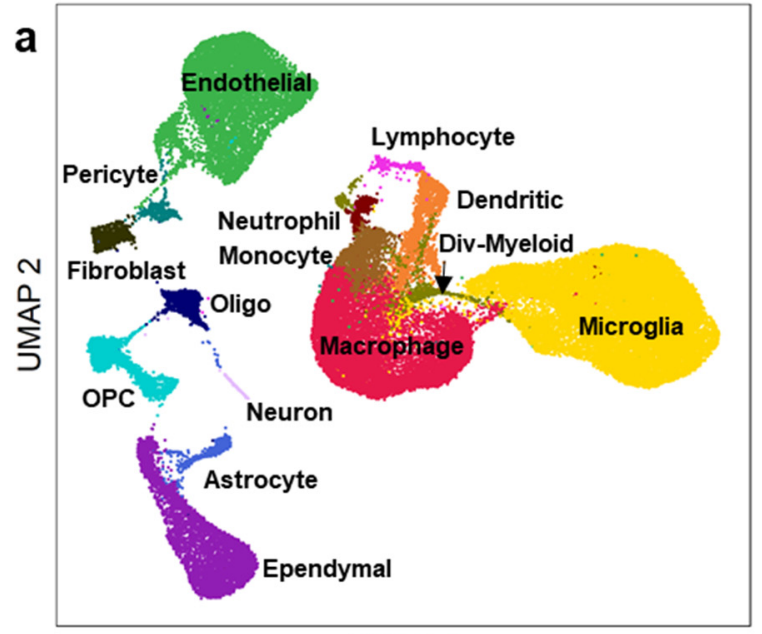

UMAP 1

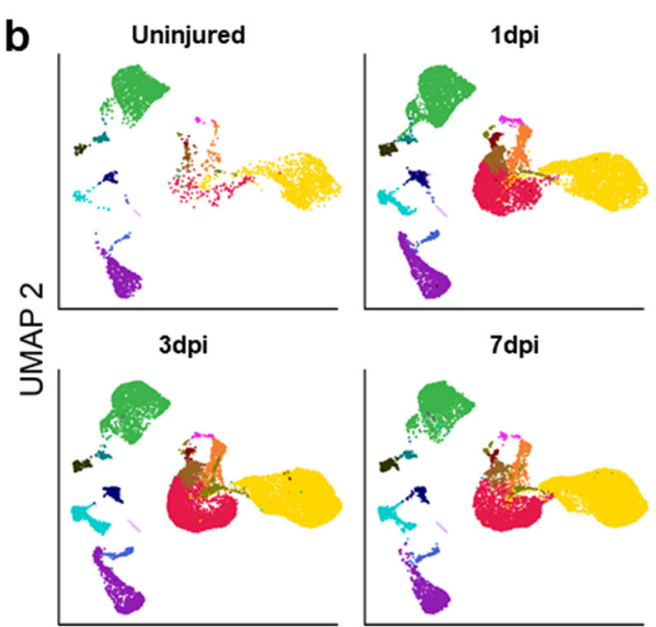

UMAP 1
Neutrophil (455)

Monocyte (1757)

Macrophage (10545)

Dendritic (1676)

Microglia (17334)

Div-Myeloid (848)

Fibroblast (825)

Endothelial (8757)

Pericyte (431)

OPC (1933)

Oligodendrocyte (1001)

Astrocyte (746)

Ependymal (4783)

Lymphocyte (455)

Neuron (297)

\section{C}
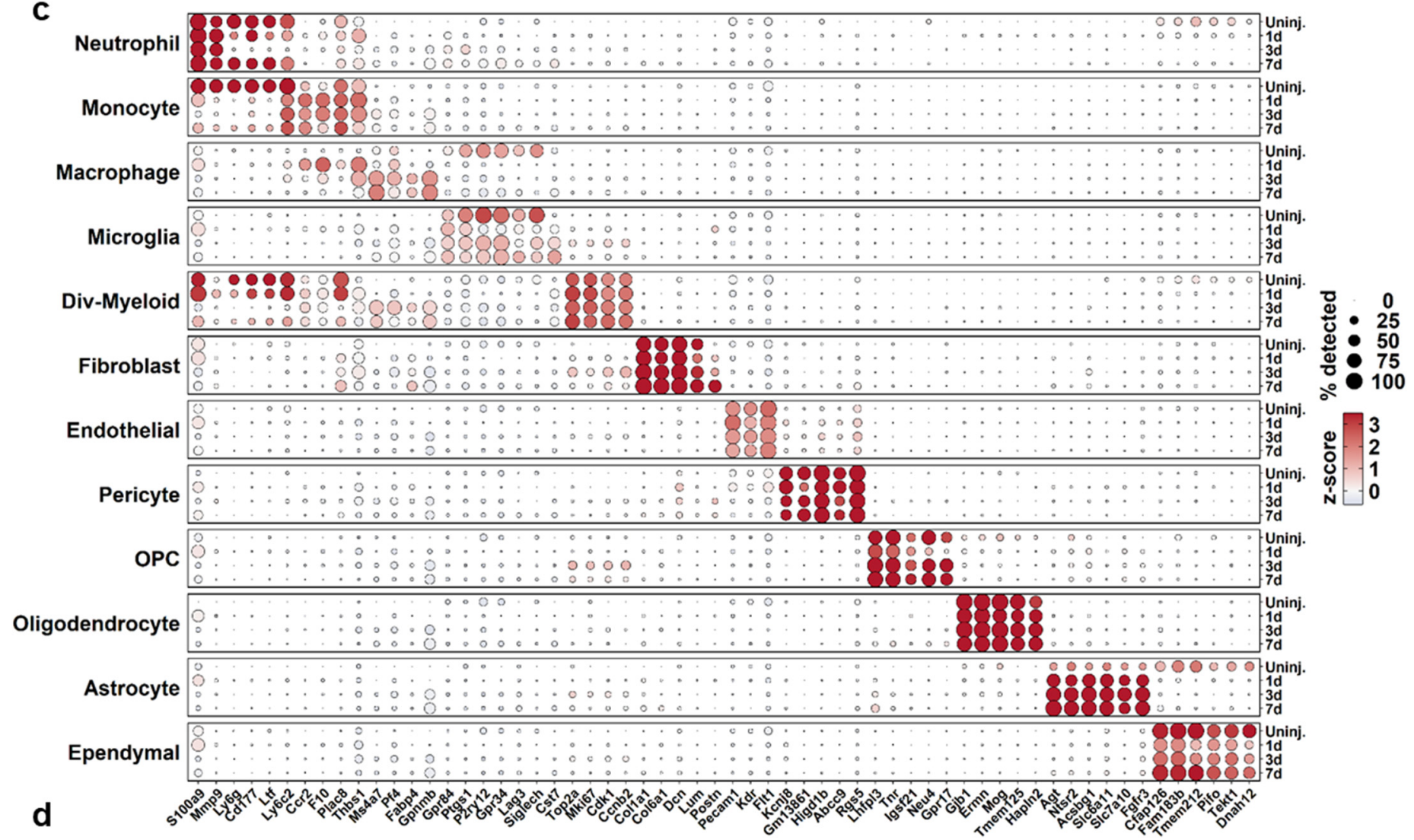

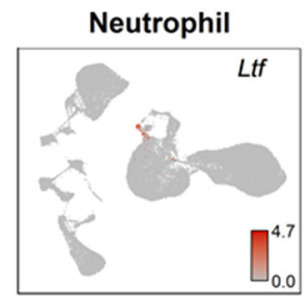

Endothelial

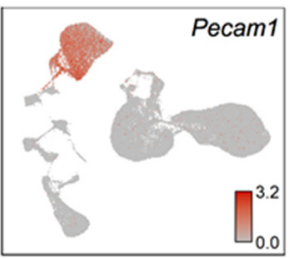

Monocyte

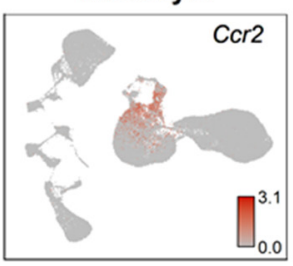

Pericyte

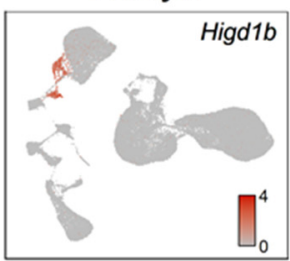

Macrophage

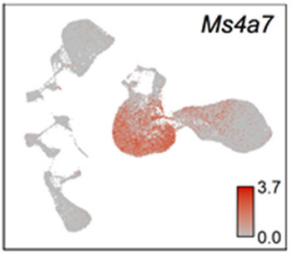

OPC

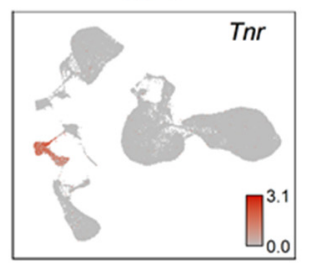

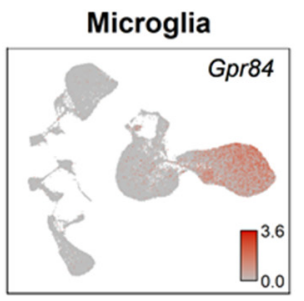

Oligodendrocyte

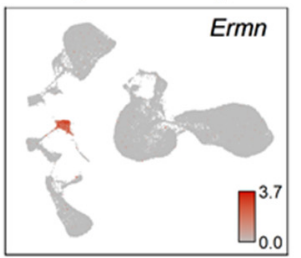

Div-Myeloid

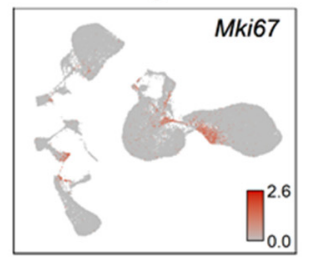

Astrocyte

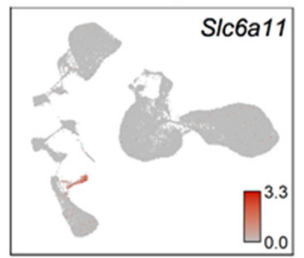

Fibroblast

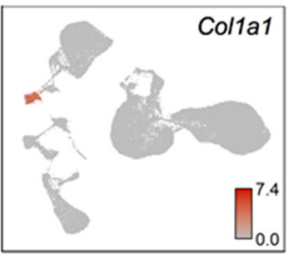

Ependymal

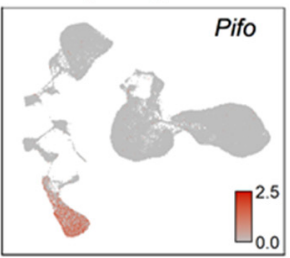

Figure 1 
bioRxiv preprint doi: https://doi.org/10.1101/2020.05.13.094854; this version posted May 14,2020 . The copyright holder for this preprint (which

was not certified by peer review) is the author/funder, who has granted bioRxiv a license to display the preprint in perpetuity. It is made available under aCC-BY-NC-ND 4.0 International license.

Fig. 1| Transcriptomic identification of major cell types that comprise the spinal cord injury site at acute

time points. (a) UMAP visualization of all cells from the uninjured, 1, 3, and $7 \mathrm{dpi}$ spinal cord displays all major cell types that are known to comprise the injury site. Clusters were identified based on expression of annotated genes for each cell type (Extended Data Fig. 1). (b) UMAP of each time point shows temporal progression of each major cell type. (c) Dot plot of highest differentially expressed genes (DEG) for each major cell type at each time point (right axis). Dot color intensity represents the z-score of expression values, and dot size represents the percentage of cells in each cell type expressing the DEG. (d) Expression pattern of the DEG that best identifies each cell type. $n=2$ biological replicates at each time point. 
bioRxiv preprint doi: https://doi.org/10.1101/2020.05.13.094854; this version posted May 14,2020 . The copyright holder for this preprint (which was not certified by peer review) is the author/funder, who has granted bioRxiv a license to display the preprint in perpetuity. It is made available under aCC-BY-NC-ND 4.0 International license.

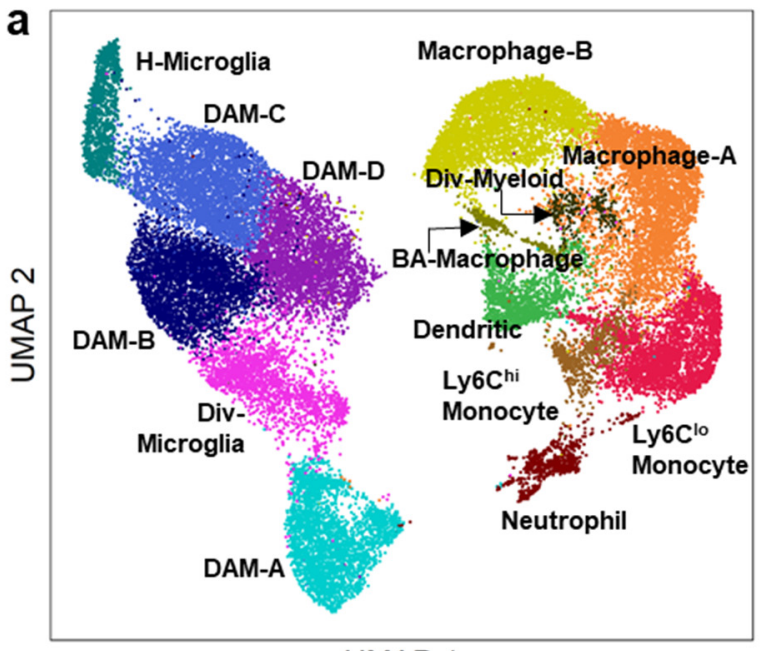

UMAP 1

C

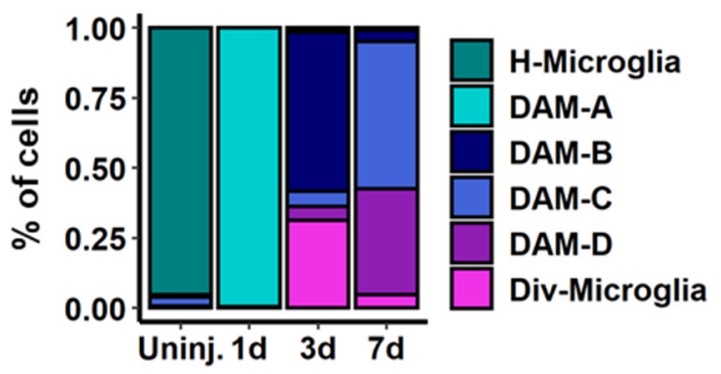

d

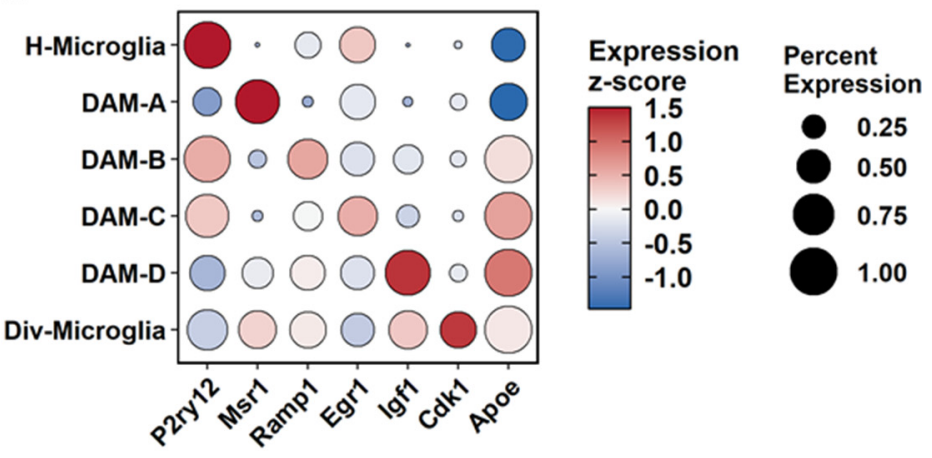

f

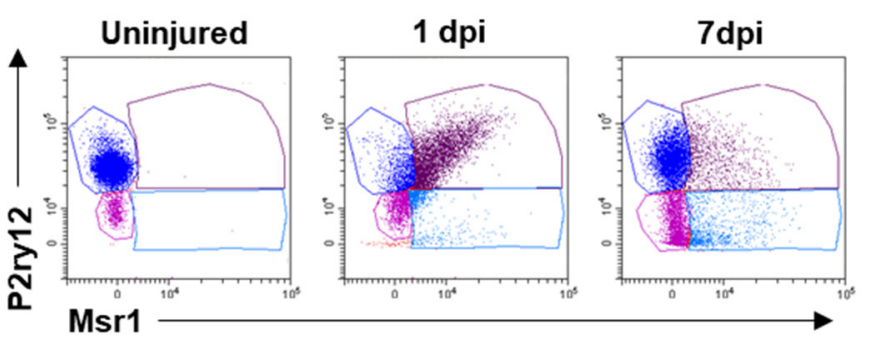

g

Microglia Subcluster Proportion

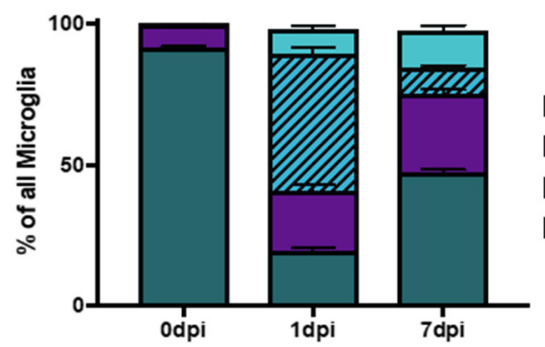

272 P2ry12 Hi/MSR1 Hi (DAM-A)

$\square$ P2ry12 Lo/MSR1 Lo (Other DAMs)

P2ry12 Lo/MSR1 Hi (DAM-A)

P2ry12 Hi/ MSR1 Lo (Homeostatic) b

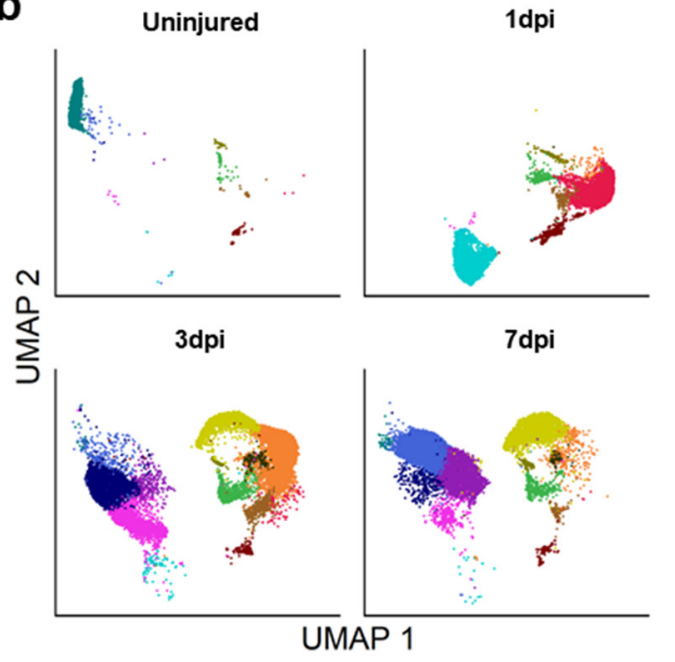

e

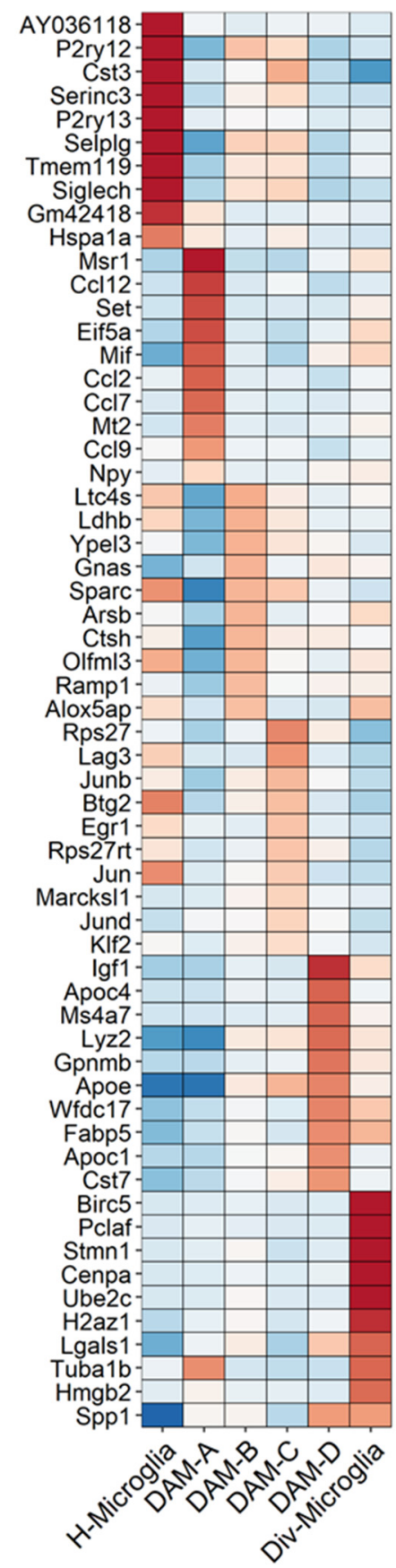

Expression

z-score

1.5

$-1.0$

$-0.5$

$-0.0$

$-0.5$

$-1.5$
Neutrophil (796)

Macrophage-A (4424)

Macrophage-B (3980)

(1310)

H-Microglia (1327)

DAM-C (4263)

DAM-D (3118)

Div-Microglia (2100) 
bioRxiv preprint doi: https://doi.org/10.1101/2020.05.13.094854; this version posted May 14,2020 . The copyright holder for this preprint (which

was not certified by peer review) is the author/funder, who has granted bioRxiv a license to display the preprint in perpetuity. It is made available under aCC-BY-NC-ND 4.0 International license.

Fig. 2| Molecular and temporal profile of microglia subtype heterogeneity acutely after SCI (a) UMAP visualization of all myeloid cell clusters combined from uninjured, 1, 3, and 7dpi. Clusters were identified based on previously annotated cell types (Extended Data Fig. 3). Four subtypes of Disease-Associated Microglia (DAM) were labeled DAM-A to D. (b) UMAP of each time point displays temporal progression of each myeloid population. (c) Percent of each microglia subtype at each time point. Dot plot of the best marker genes (d) as well as a heat map of the highest DEGs shows a unique expression profile for each microglia subtype. Scatter plot (f) and quantification $(\mathrm{g})$ of flow cytometry analysis to validate the presence of DAM-A and its temporal changes after SCI. $n=5$ biological replicates for each time point in flow cytometry experiment. 
bioRxiv preprint doi: https://doi.org/10.1101/2020.05.13.094854; this version posted May 14, 2020. The copyright holder for this preprint (which was not certified by peer review) is the author/funder, who has granted bioRxiv a license to display the preprint in perpetuity. It is made available under aCC-BY-NC-ND 4.0 International license.

a

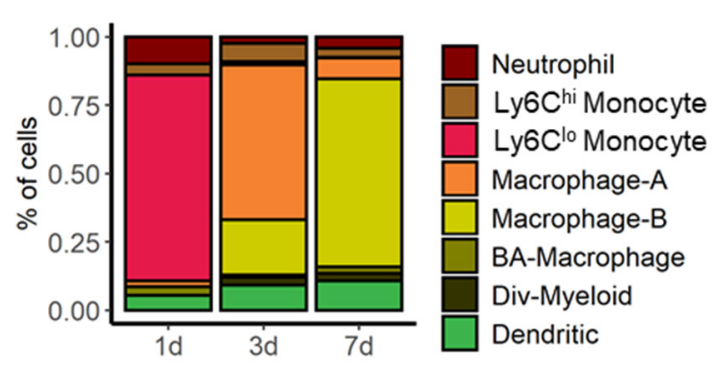

b

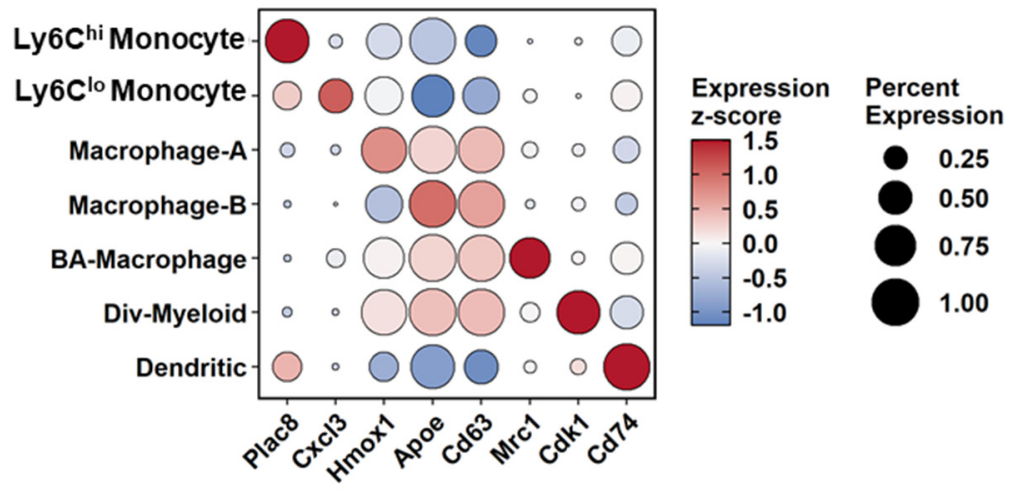

d
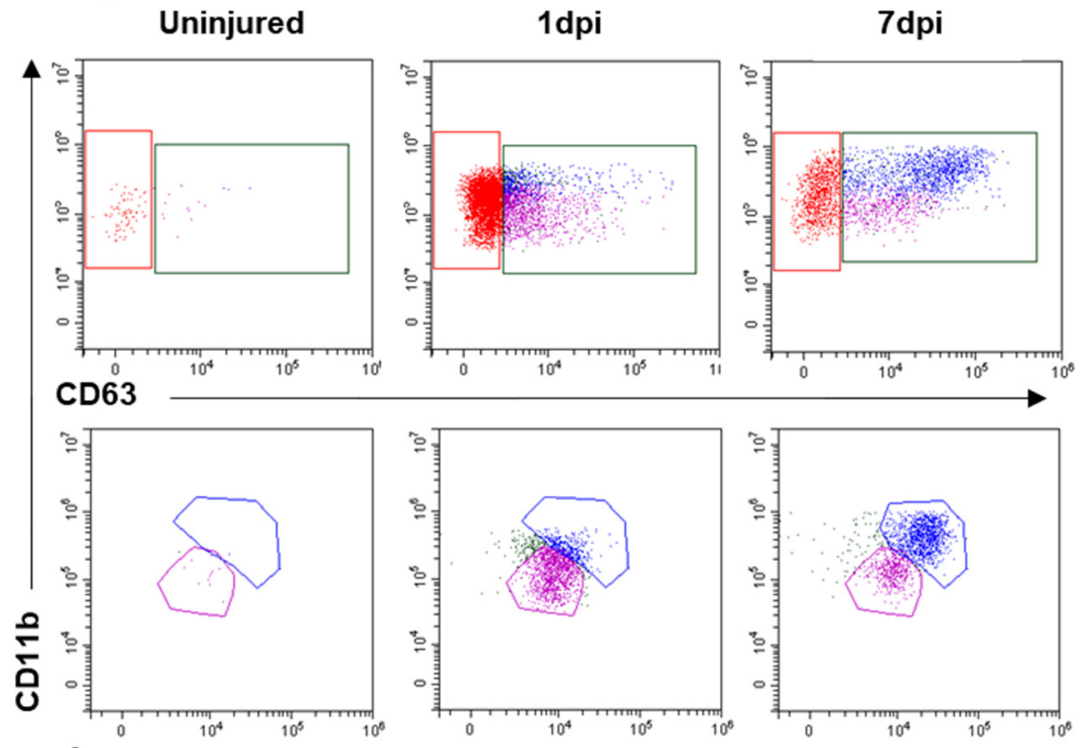

Apoe

\section{e}

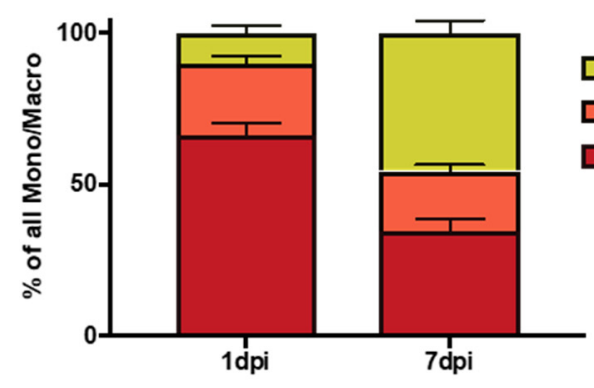

CD63 $+A p o E^{\text {hi }}$ (Mac-B)

CD63 ${ }^{+} / \mathrm{ApoE}^{\mathrm{lo}}$ (Mac-A)

CD63- (Monocytes)

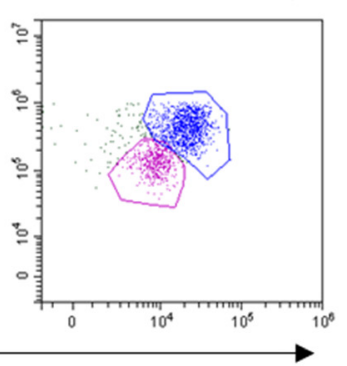

C

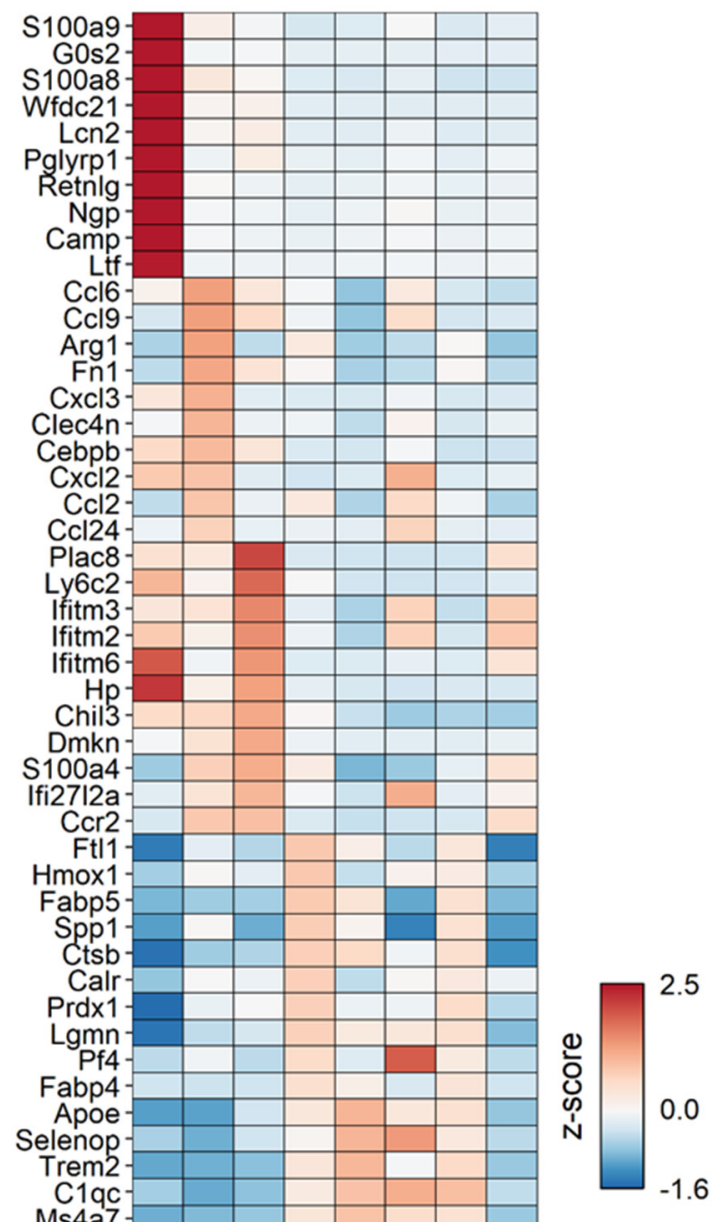

Figure 3 
bioRxiv preprint doi: https://doi.org/10.1101/2020.05.13.094854; this version posted May 14, 2020. The copyright holder for this preprint (which

was not certified by peer review) is the author/funder, who has granted bioRxiv a license to display the preprint in perpetuity. It is made available under aCC-BY-NC-ND 4.0 International license.

Fig. 3| Molecular and temporal profile of monocyte/macrophage subtype heterogeneity acutely after SCI.

(a) Percent of each peripheral myeloid subtype at each time point. (b) Dot plot of the best marker genes (c) as well as a heat map of the highest DEGs shows a unique expression profile for each peripheral myeloid subtype.

Scatter plot (d) and quantification (e) of flow cytometry analysis to validate the presence of Macrophage-A and $\mathrm{B}$ and their temporal changes after $\mathrm{SCI} . \mathrm{n}=5$ biological replicates at each time point for flow cytometry experiment. 
bioRxiv preprint doi: https://doi.org/10.1101/2020.05.13.094854; this version posted May 14, 2020. The copyright holder for this preprint (which was not certified by peer review) is the author/funder, who has granted bioRxiv a license to display the preprint in perpetuity. It is made available under aCC-BY-NC-ND 4.0 International license.

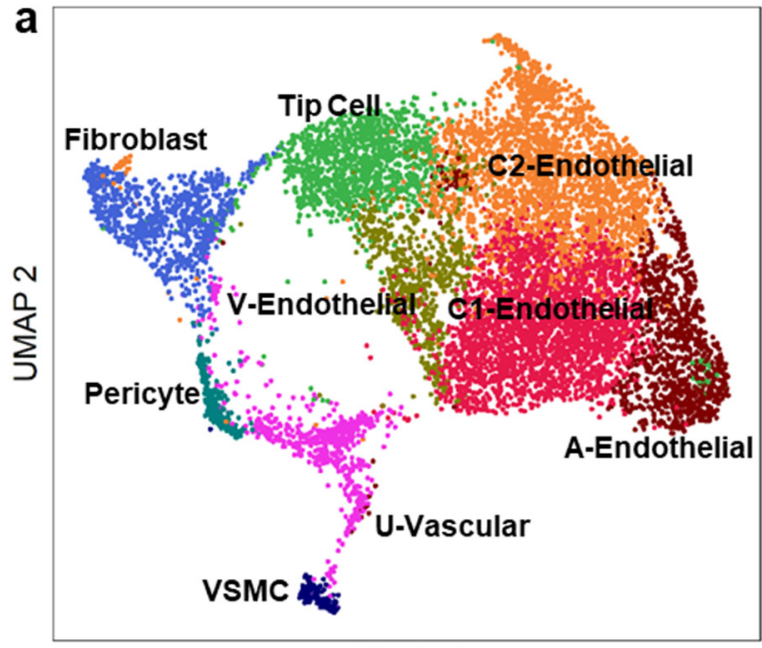

UMAP 1

C

$\mathbf{f}$

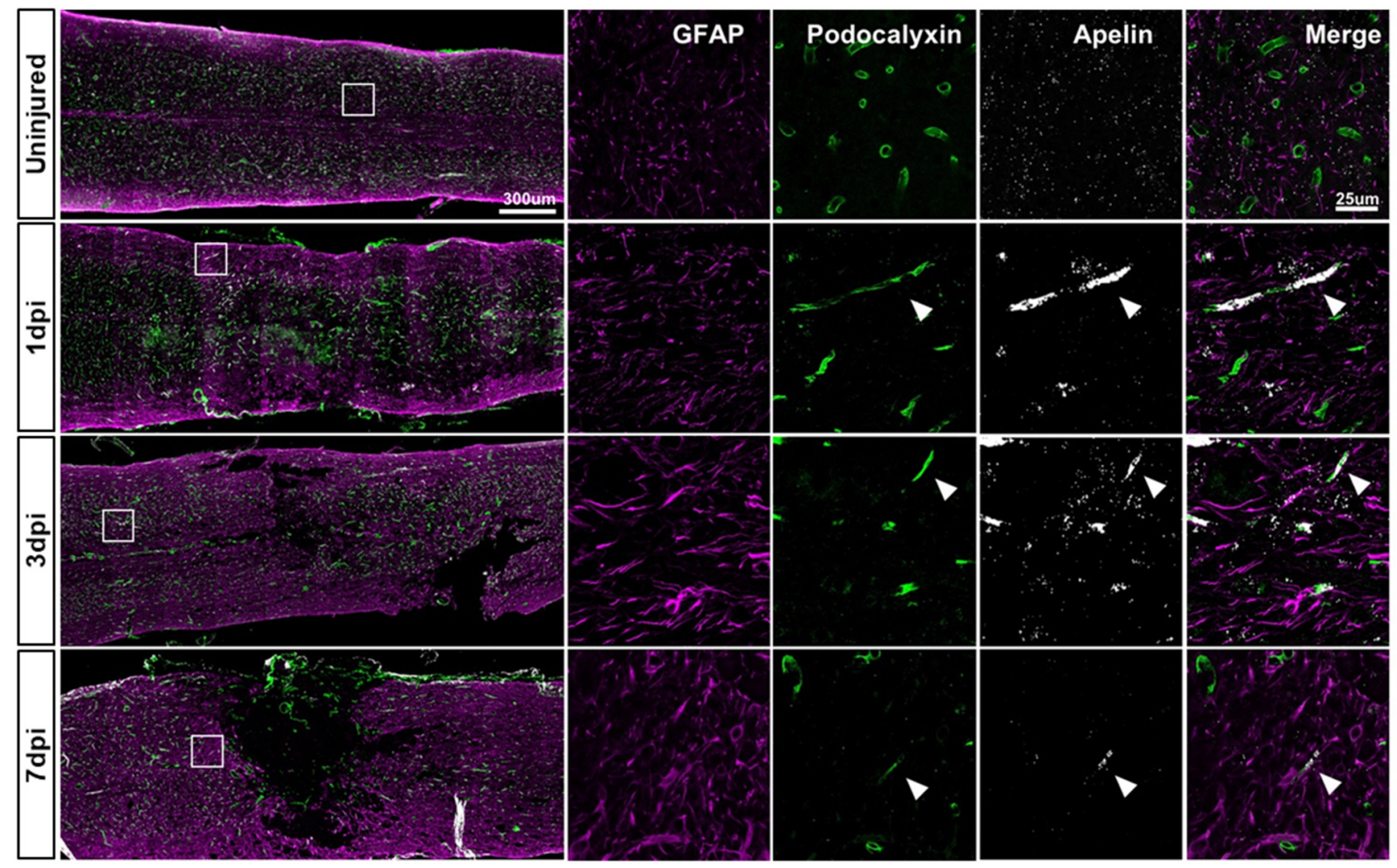

b Uninjured 1dpi

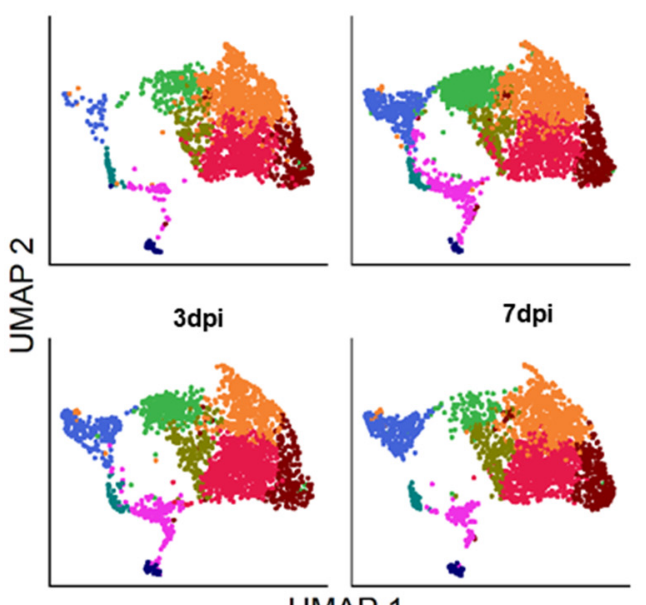

UMAP 1

d

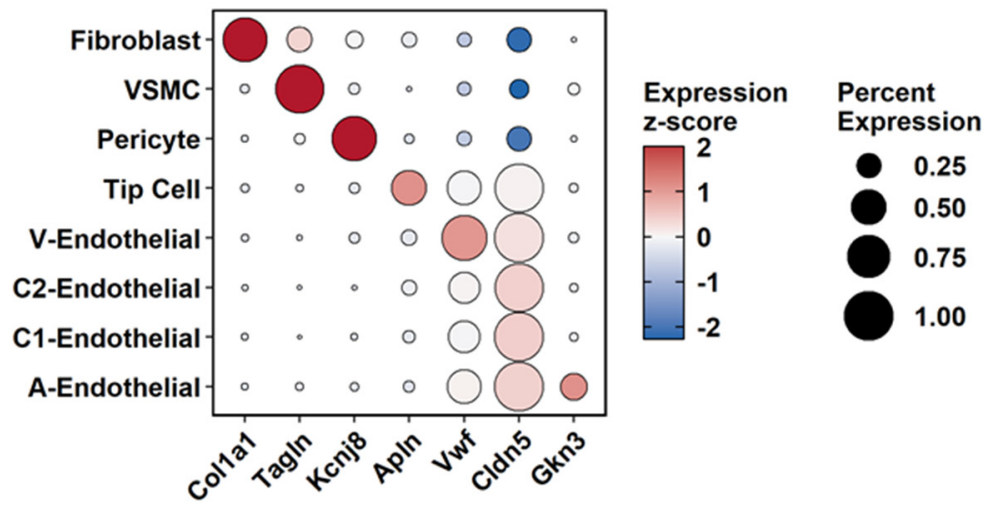

A-Endothelial (966)

C1-Endothelial (2683)

C2-Endothelial (2355)

V-Endothelial (642)

Tip Cell (1171)

Pericyte (244)

VSMC (135)

Fibroblast (898)

U-Vascular (561)

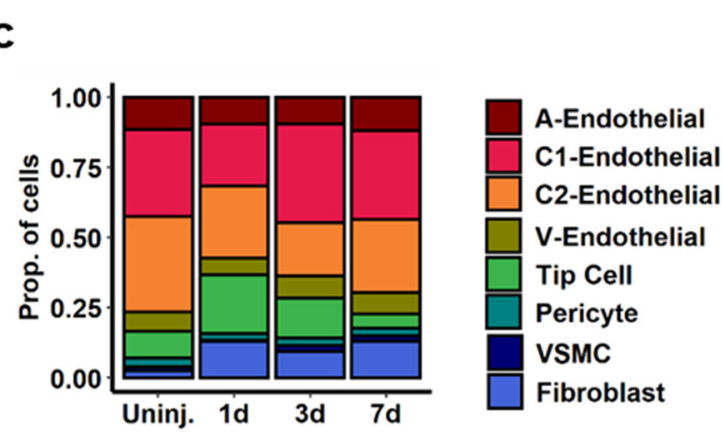

f 
Fig. 4| Molecular and temporal profile of vascular cell subtype heterogeneity acutely after SCI. (a) UMAP

visualization of vascular cell clusters combined from uninjured, 1, 3, and $7 \mathrm{dpi}$. Clusters were identified by previously annotated genes (Extended Data Fig. 7). (b) UMAP of each time point shows temporal progression of each cluster. (c) Quantification of the number and proportion of each cluster over time after injury. (d) Dot plot of the marker gene that best identifies each cell type. (f) Histological validation of the temporal progression of tip cells at the injury site. Uninjured, 1, 3, and 7dpi spinal cord sections were assessed by immunohistochemistry for podocalyxin (endothelial cells) combined with in situ hybridization for apelin (tip cells). GFAP was used as a marker for astrocytes to delineate the injury site. White box represents the corresponding region of the magnified images on the right. Arrow heads identify tip cells that co-express podocalyxin and apelin. Representative images from a total of 5 animals. 
bioRxiv preprint doi: https://doi.org/10.1101/2020.05.13.094854; this version posted May 14, 2020. The copyright holder for this preprint (which was not certified by peer review) is the author/funder, who has granted bioRxiv a license to display the preprint in perpetuity. It is made available under ACC-BY-NC-ND 4.0 International license.

a

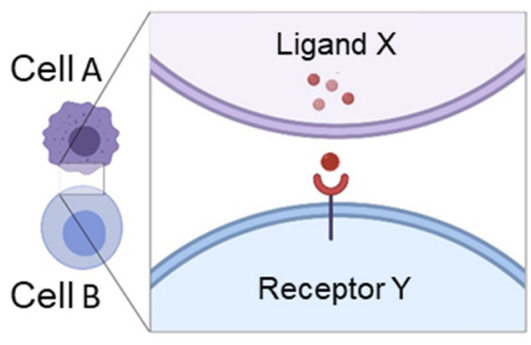

Interaction Score $=$

$\frac{\log \left(\text { Ligand }_{X}\right)_{\text {Cell A }}+\log \left(\text { Receptory }_{Y}\right)_{\text {Cell B }}}{2}$

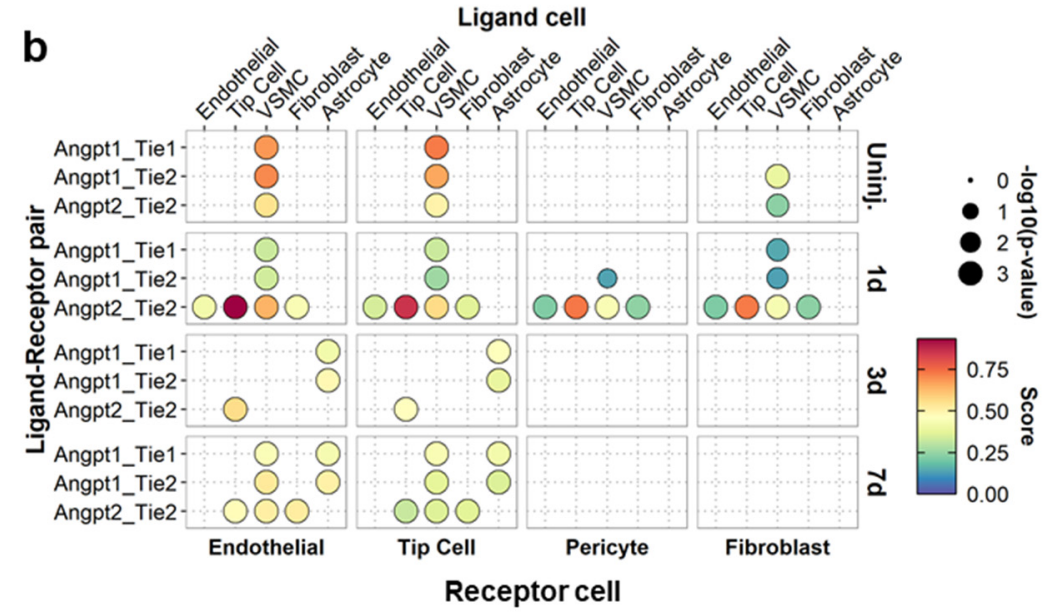

C

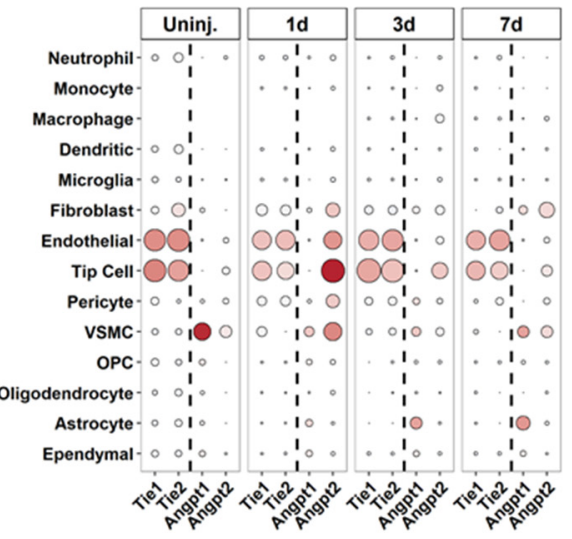

Vascular Destabilization
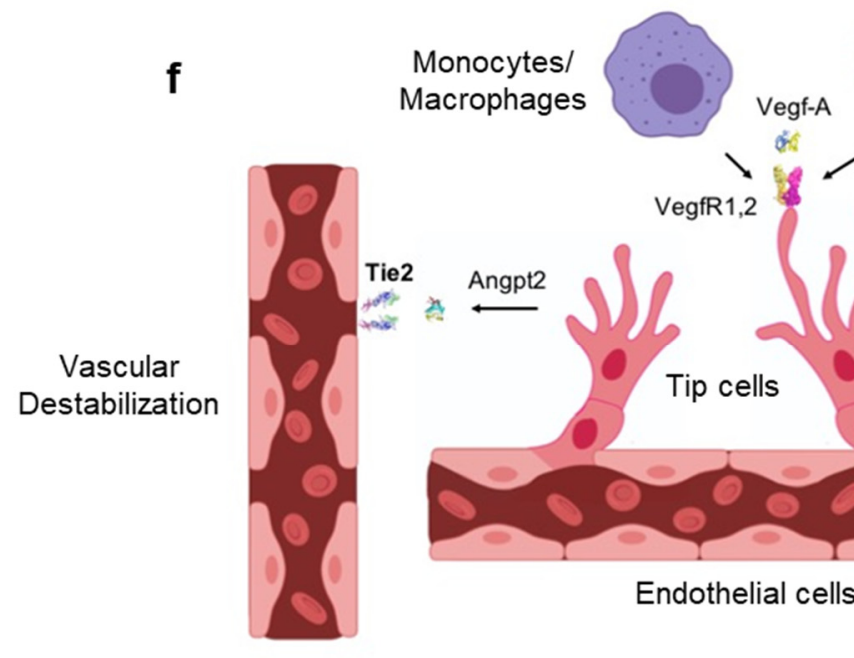

d

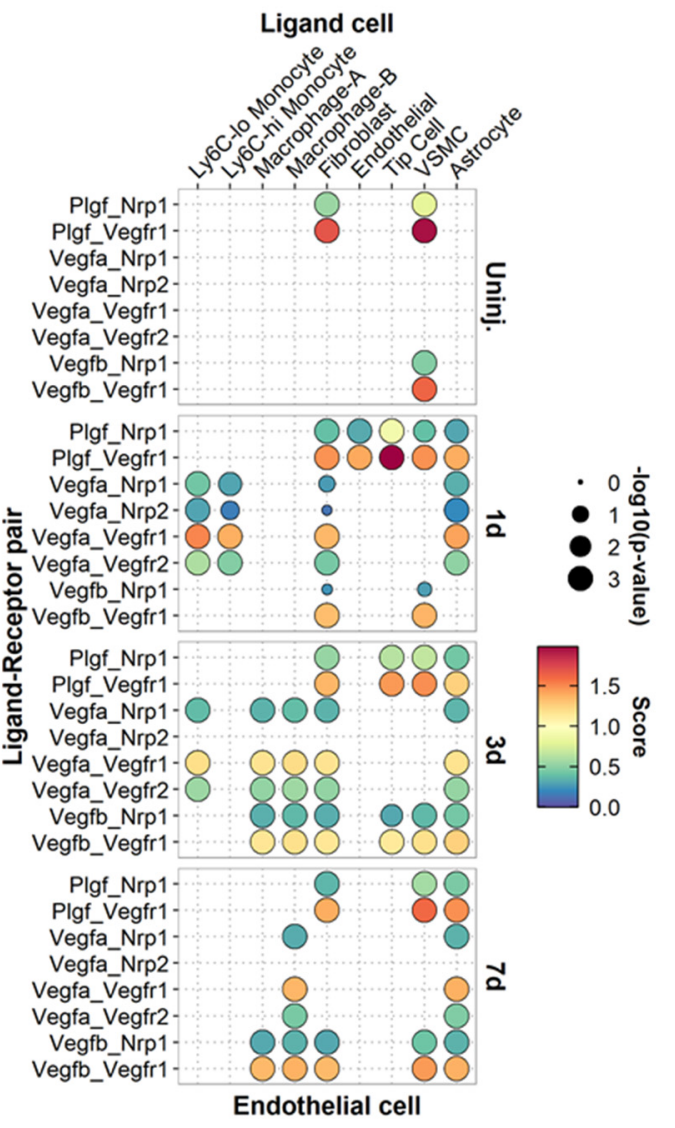

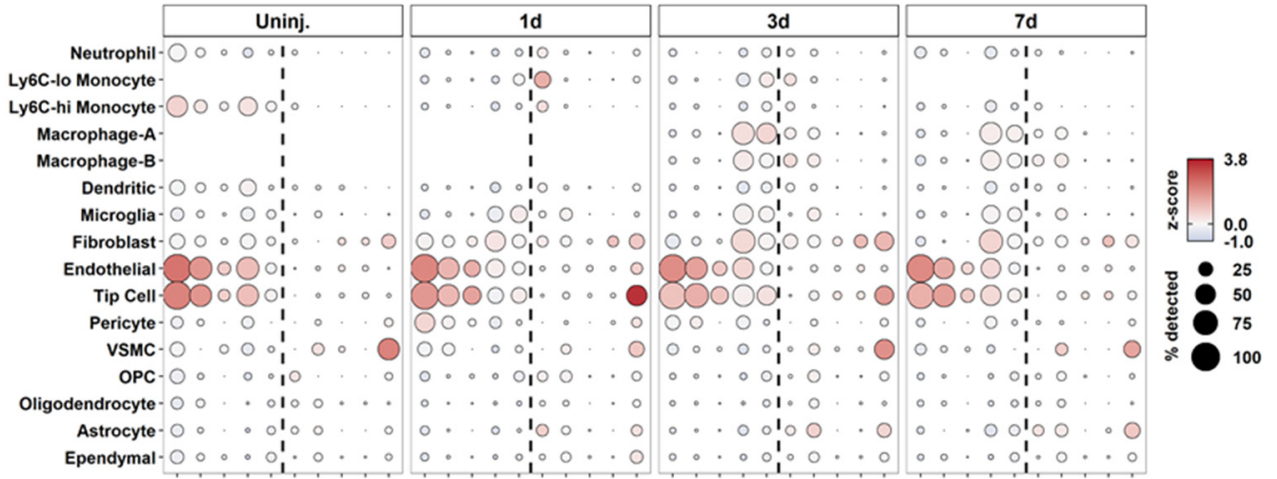

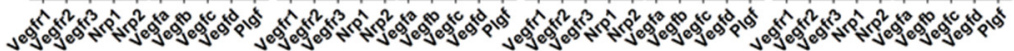

Monocytes/ Macrophages

Astrocytes
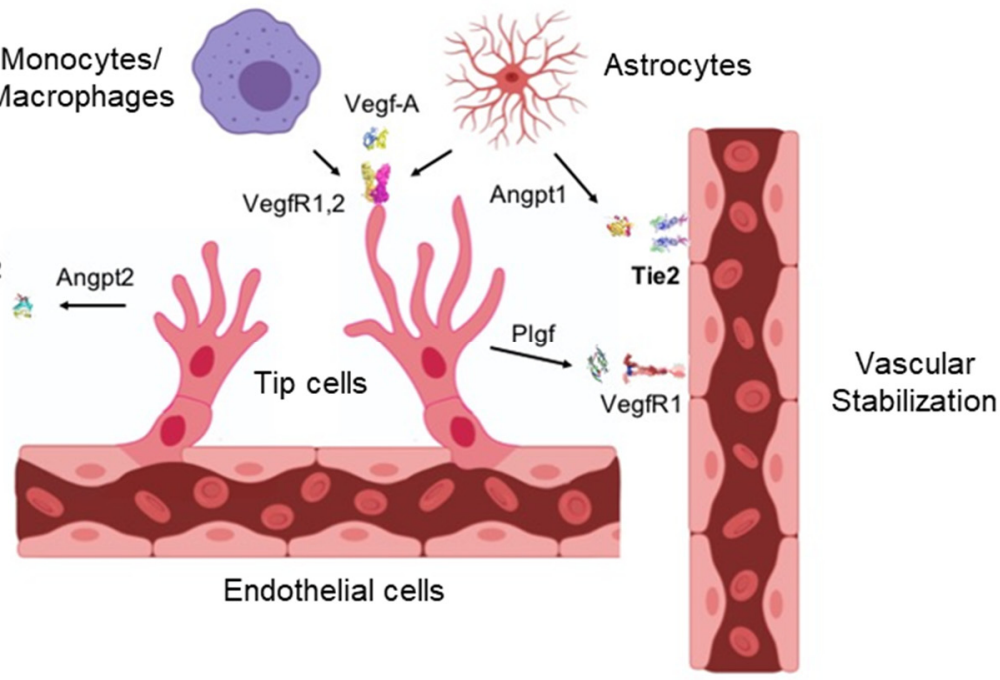

Figure 5 
Fig. 5| Ligand-receptor analysis of angiopoietin and vegf signaling reveals vascular interactions. (a)

Interaction Score was calculated by the average of ligand expression in one cell type and receptor expression in another. Expression values were from a cell type cluster, and not from a single cell. (b) Dot plot of the interaction scores for angiopoietin signaling. Ligand expressing cells are listed on the top, and receptor expressing cells are on the bottom. The ligand-receptor pairs are listed on the left. Size of the circle denotes $p$ value, and color denotes interaction score. (c) Dot plot of expression values of angiopoietins and their receptors in each major cell type. (d) Dot plot of the interaction scores for vegf signaling. (e) Dot plot of expression values of certain vegf family members and their receptors in each major cell type. (f) Schematic depicting minimal model of vascular interactions via angiopoietin and vegf signaling during angiogenesis after SCl. 
bioRxiv preprint doi: https://doi.org/10.1101/2020.05.13.094854; this version posted May 14, 2020. The copyright holder for this preprint (which was not certified by peer review) is the author/funder, who has granted bioRxiv a license to display the preprint in perpetuity. It is made available under aCC-BY-NC-ND 4.0 International license.

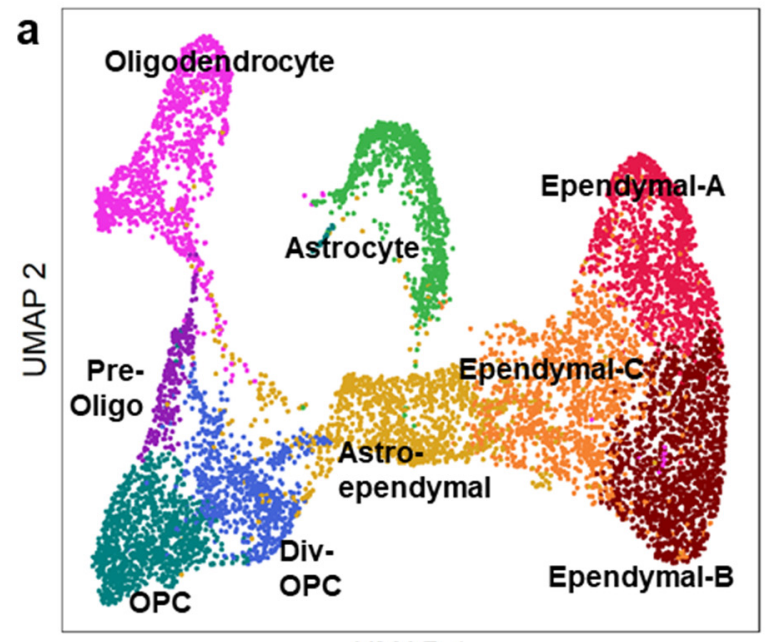

UMAP 1

C

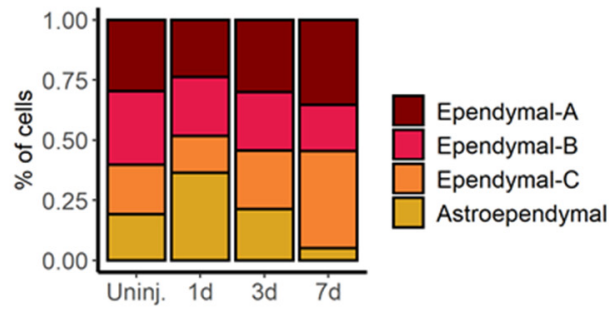

d

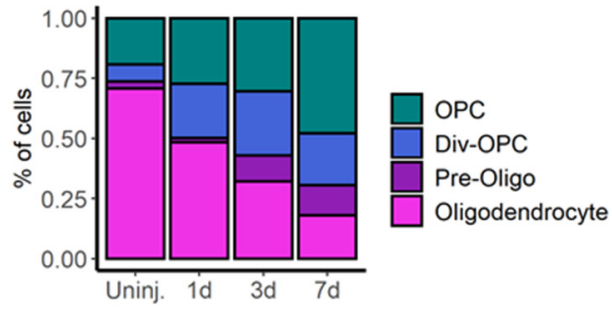

f

\begin{tabular}{r}
\hline Astrocyte GO \\
Ribosome biogenesis \\
Cytoplasmic translation \\
Cell nitrogen comp biosyn \\
Response to stress \\
Cell component biogenesis \\
Reg of neurogenesis \\
Reg cell development \\
Reg neuron differentiation \\
Gliogenesis \\
Neuron projection dev
\end{tabular}

Plasma lipoprot particle org Protein-lipid complex subunit org Pos reg of cholesterol efflux

Reg plasma lipoprotein particle Protein-lipid complex remodeling b
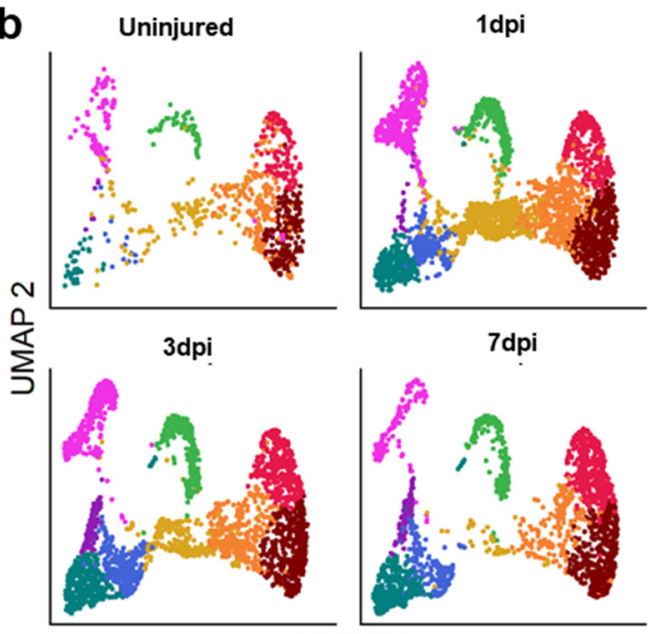

Ependymal-A (1344)

Ependymal-B (1115)

Ependymal-C (1124)

Astroependymal (1078)

Astrocyte (792)

OPC (998)

Div-OPC (694)

Pre-Oligo (238)

Oligodendrocyte (1080)

UMAP 1

e

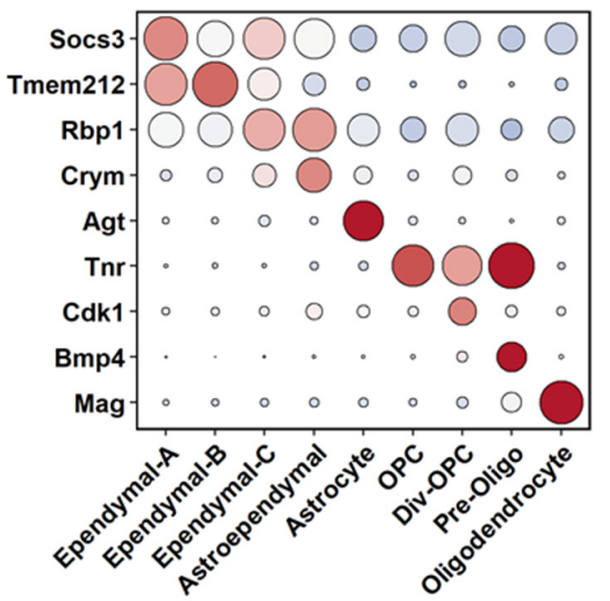

Inhibitors of axonal growth

g

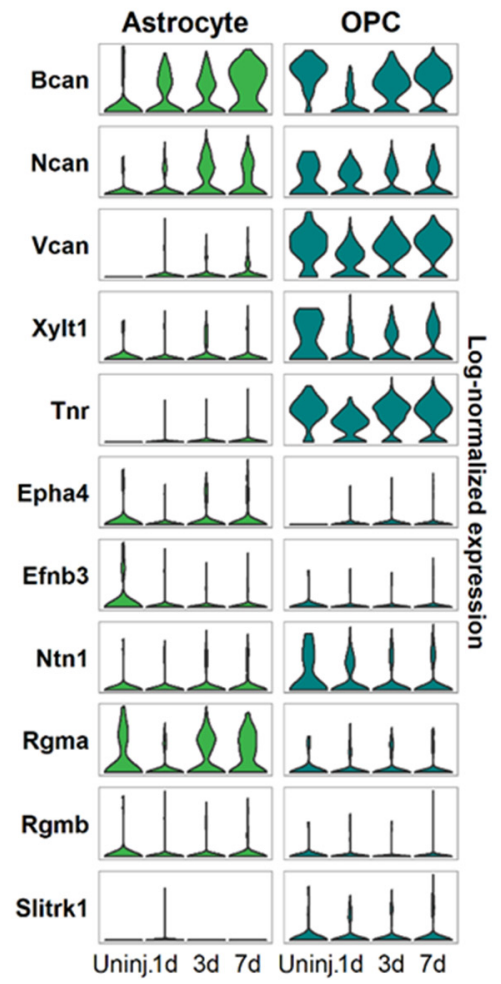

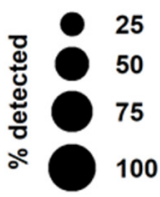

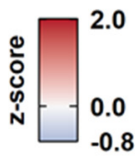

Cell protein metab process Cell nitrogen compound biosyn Cytoplasmic translation Cellular component biogenesis rRNA proc ing??

Mitotic cell cycle

Cell division

Mitotic cell cycle proc

Mitotic cell phase transition

Chromosome segregation

Astrocyte development

Synapse pruning

Reg of response to ext stim

Reg of inflammatory response

Synapse organization 
bioRxiv preprint doi: https://doi.org/10.1101/2020.05.13.094854; this version posted May 14,2020 . The copyright holder for this preprint (which

was not certified by peer review) is the author/funder, who has granted bioRxiv a license to display the preprint in perpetuity. It is made available under aCC-BY-NC-ND 4.0 International license.

Fig. 6| Molecular and temporal profile of macroglial heterogeneity acutely after SCI. (a) UMAP visualization

of macroglial cell clusters combined from uninjured, 1, 3, and 7dpi. Clusters were identified by previously annotated genes (Extended Data Fig. 8). (b) UMAP of each time point shows temporal progression of each cluster. (c) Quantification of the number and proportion of each ependymal and (d) other macroglial clusters over time after injury. (e) Dot plot of the marker gene that best identifies each cell type. (f) Comparison between astrocyte and OPC Gene Ontology biological processes based on DEG between sequential time points. GO terms are listed in rank order from top to bottom for each time point. Remaining GO terms are in Expanded Data Fig. 9. (g) Comparison of expression of common axon growth inhibitors between astrocytes and OPCs. 
bioRxiv preprint doi: https://doi.org/10.1101/2020.05.13.094854; this version posted May 14,2020 . The copyright holder for this preprint (which was not certified by peer review) is the author/funder, who has granted bioRxiv a license to display the preprint in perpetuity. It is made available under aCC-BY-NC-ND 4.0 International license.
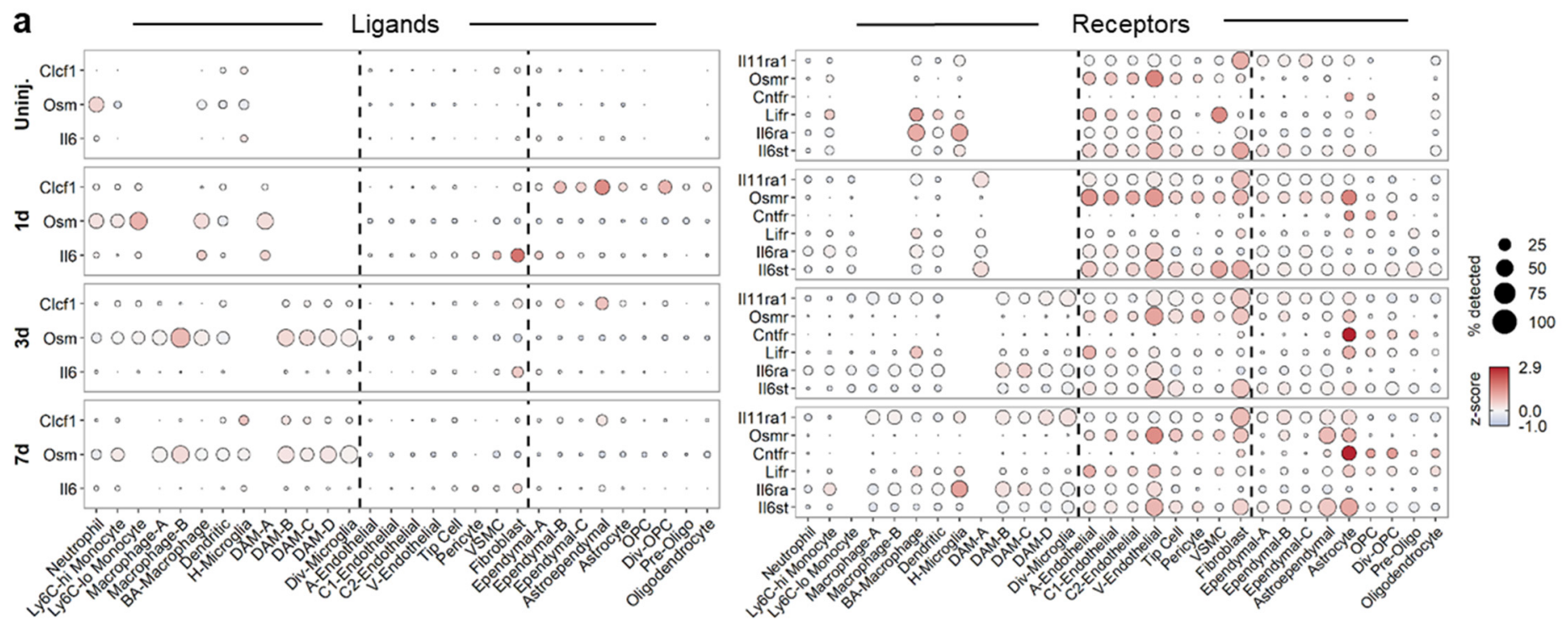

b

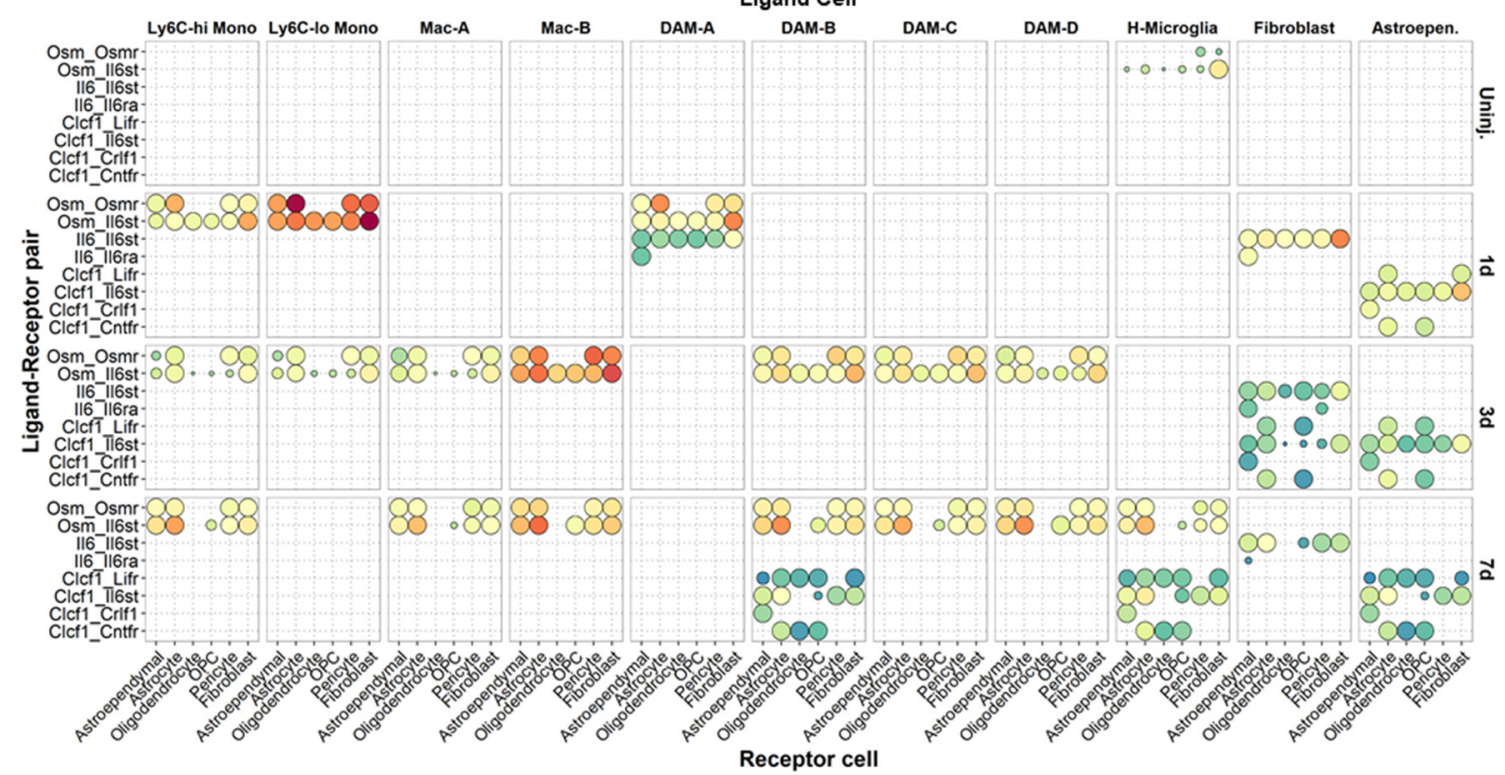

C
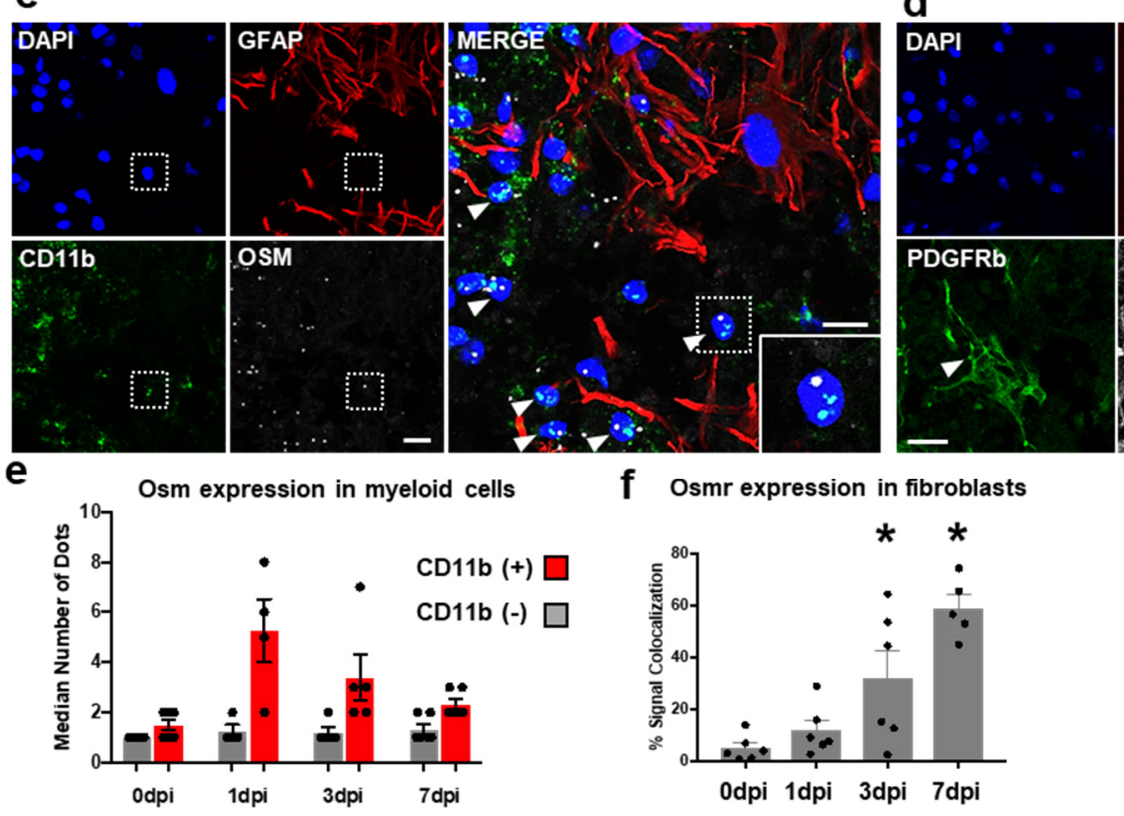

f Osmr expression in fibroblasts

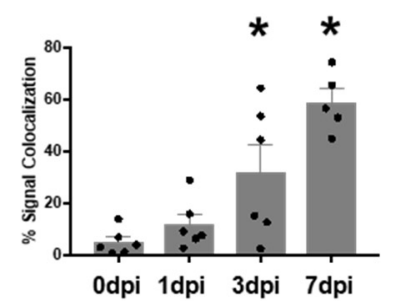

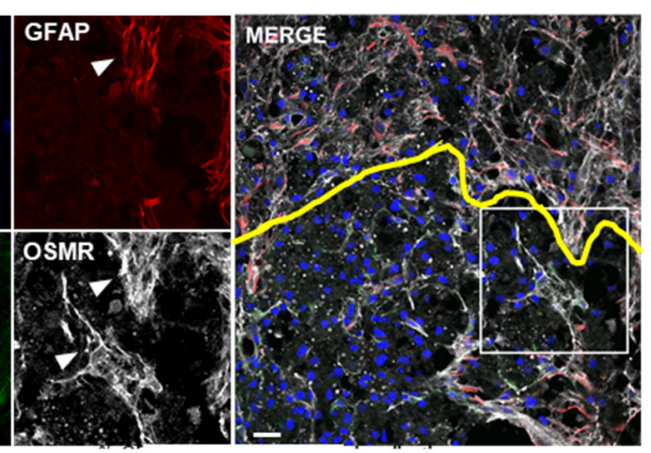

g Osmr expression in astrocytes

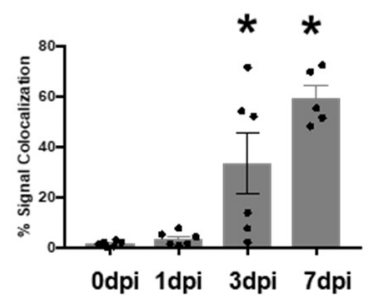

Figure 7 
Fig.7| Ligand-receptor analysis of IL6 cytokine family members identify Oncostatin M signaling between myeloid cells and astrocytes/fibroblasts. (a) Dot plot depicting expression levels of IL6 family member ligands and receptors. The size of the dot depicts the percent of cells expressing the gene at the given time. Ligands/receptors not on the list did not reach statistical significance or were not present in the sequencing data.

(b) Dot plot of interaction scores of IL6 family member signaling show highest predicted interaction between myeloid cells and astrocytes/fibroblasts via oncostatin M signaling. (c) Histological validation of oncostatin M expression in myeloid cells. Spinal cord sections were assessed by immunohistochemistry for GFAP (astrocytes) combined with in situ hybridization for CD11b (myeloid) and Osm (oncostain M). DAPI denotes cell nuclei. (d) Histological validation of oncostatin $\mathrm{M}$ receptor (Osmr) expression in astrocytes and fibroblasts. Spinal cord sections were assessed by immunohistochemistry for GFAP (astrocytes), Pdgfr- $\beta$ (fibroblasts), and Osmr. Yellow line delineates astroglial scar border. (e) Quantification of Osm expression in myeloid (DAPI $/ \mathrm{CD} 11 \mathrm{~b}^{+} / \mathrm{Osm}^{+}$) and non-myeloid $\left(\mathrm{DAPI}^{+} / \mathrm{CD} 11 \mathrm{~b} / \mathrm{Osm}^{+}\right)$cells shows significantly higher Osm expression in myeloid cells. Quantification showed increasing colocalization of Osmr with Pdgfr- $\beta$ (f) or GFAP (g) immunoreactivity over time. Error bars represent SEM. * $\mathrm{p}<0.05$ compared to 0dpi. One-Way ANOVA and Tukey's post-hoc test. Images are from 7 dpi. Scale bar $=15 \mu \mathrm{m}$. Each data point represents a biological replicate. 
bioRxiv preprint doi: https://doi.org/10.1101/2020.05.13.094854; this version posted May 14,2020. The copyright holder for this preprint (which was not certified by peer review) is the author/funder, who has granted bioRxiv a license to display the preprint in perpetuity. It is made available under aCC-BY-NC-ND 4.0 International license.

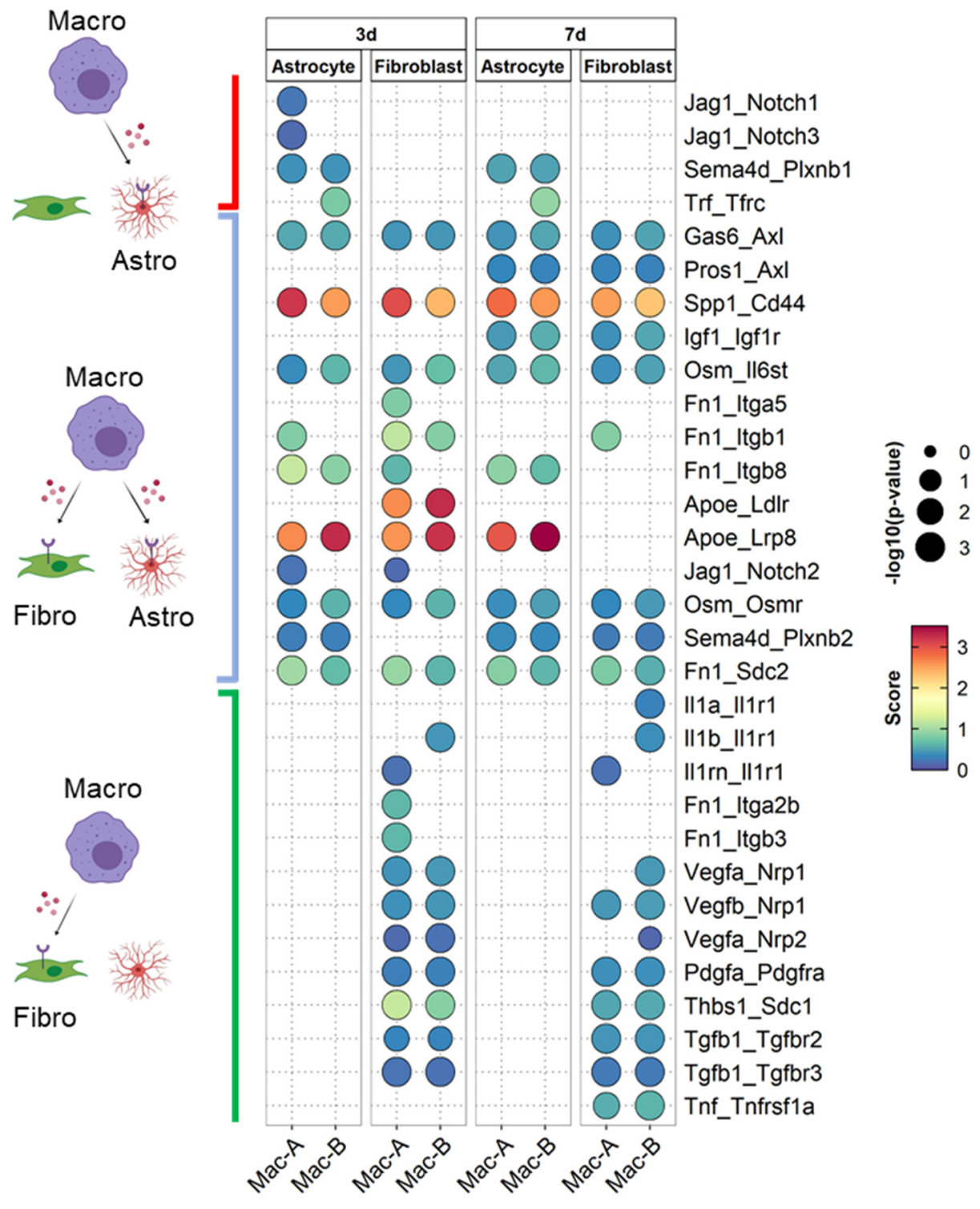

Figure 8 
bioRxiv preprint doi: https://doi.org/10.1101/2020.05.13.094854; this version posted May 14, 2020. The copyright holder for this preprint (which

was not certified by peer review) is the author/funder, who has granted bioRxiv a license to display the preprint in perpetuity. It is made available under aCC-BY-NC-ND 4.0 International license.

Fig. 8| Macrophage subtypes interact with astrocytes and fibroblasts via distinct and common signaling

pathways. Dot plot of interaction scores for all ligand-receptor pairs at 3 and 7 dpi showed signaling specific between macrophages and astrocytes (red bracket on top) as well as between macrophages and fibroblasts (green bracket on bottom). Common pathways are indicated by the blue bracket in the middle. Macrophage subtypes (A or B) are denoted at the bottom. 